\title{
Empleo Informal y Apertura Comercial: Evidencia de 20 años de Reformas en Argentina
}

\author{
Tesis \\ Maestría en Economía \\ Universidad Nacional de La Plata \\ Mariana Viollaz \\ Director: Guillermo Cruces
}

\begin{abstract}
Resumen
Este trabajo estudia la relación entre las reformas comerciales y el fenómeno de informalidad laboral en las industrias manufactureras del Gran Buenos Aires durante el período 1980-2001. La combinación de información sobre tarifas a las importaciones y microdatos de la fuerza laboral permite diseñar una estrategia de identificación basada en la variabilidad del grado de protección entre industrias a lo largo del tiempo. Los resultados obtenidos respaldan las teorías que indican que ante la apertura comercial las firmas buscarán reducir costos siendo uno de los posibles mecanismos el incremento en la informalidad laboral, ya sea eliminando los beneficios jubilatorios de sus empleados o despidiendo trabajadores que luego son incorporados como empleados informales por otras firmas de la misma industria. Más específicamente, la liberalización comercial explica un $4 \%$ del aumento observado en la tasa de informalidad de las industrias del sector manufacturero durante el período analizado.
\end{abstract}

\footnotetext{
* Agradezco a Guillermo Cruces por la dirección y coordinación de este trabajo de tesis; a Andrés Ham, David Jaume y Juan Ignacio Zoloa por sus comentarios y sugerencias y a Guido Porto por permitirme el uso de su base de datos sobre tarifas a las importaciones.
} 


\section{Introducción}

El período comprendido entre los años 1980 y 2001 fue testigo de varios cambios en la política comercial argentina. Los primeros años, caracterizados por la aplicación de medidas de liberalización del comercio, fueron proseguidos por un período de estancamiento de las tarifas aduaneras en niveles elevados, que luego fue revertido con un amplio proceso de apertura comercial durante la década del noventa (Galiani y Porto, 2008).

Existe acuerdo respecto a que los cambios en la exposición de un país al comercio internacional resultan en una variación en la distribución de sus recursos (Goldberg y Pavcnik, 2006). Este trabajo se focaliza en un aspecto en particular de la asignación de recursos: el movimiento de trabajadores desde la formalidad hacia la informalidad. Más específicamente, se buscará precisar la relación existente entre las reformas comerciales y el fenómeno de informalidad laboral en el Gran Buenos Aires para el período 1980-2001. Para esto se utilizarán datos de tarifas a las importaciones provenientes del trabajo de Galiani y Porto (2008), quienes estudian la relación entre reformas comerciales y estructura de salarios en Argentina.

Distintos trabajos han desarrollados los argumentos que advierten sobre los posibles problemas asociados a la apertura comercial (Goldberg y Pavcnik, 2003; Bottini y Gasiorek, 2009; Fiess y Fugazza, 2008) ${ }^{1}$. Ellos sostienen que las firmas locales, al enfrentar una mayor competencia extranjera, se verán en la necesidad de reducir sus costos y esto puede ser logrado, entre otras estrategias, mediante el incumplimiento de las regulaciones del mercado laboral, reemplazando trabajadores permanentes con trabajadores temporarios, realizando el “outsourcing” de parte de sus actividades a firmas más pequeñas e informales o despidiendo trabajadores que luego obtendrán un empleo en el sector informal de la economía. Por otro lado, la reforma genera oportunidades para la entrada de nuevas firmas al mercado, que comienzan siendo pequeñas e informales.

Un potencial problema de este argumento es que firmas maximizadoras de beneficios habrían visto la oportunidad de reducir costos moviéndose hacia la informalidad antes de la reforma comercial (Goldberg y Pavcnik, 2003). Adicionalmente, lleva implícito un juicio de

\footnotetext{
${ }^{1}$ Estos argumentos serán desarrollados en la Sección 2.
} 
valor negativo respecto de la informalidad laboral. Siguiendo la línea de Maloney (2003), un incremento de la informalidad como resultado de la apertura comercial no necesariamente será calificado como no deseable desde el punto de vista del bienestar de los trabajadores. Esto ocurre porque ellos evalúan múltiples dimensiones de un empleo, de manera que la informalidad laboral no necesariamente constituye una opción inferior al empleo formal. Bajo esta perspectiva y ante la imposibilidad de capturar empíricamente todas las dimensiones o el conjunto de atributos de un empleo, no sería posible afirmar que un incremento en la informalidad laboral derivado de la política de liberalización comercial tenga un impacto negativo sobre el bienestar de los trabajadores. Sin embargo, existe evidencia para el caso del Gran Buenos Aires que indica que la mayor parte de los trabajadores informales está en dicha situación porque tiene restricciones para acceder a un trabajo formal (Waisgrais y Sarabia, 2008). Estos trabajadores, en líneas generales, están insatisfechos con sus empleos independientemente de la categoría ocupacional a la que pertenezcan. De aquí se desprende que los trabajadores informales desearían ingresar a la formalidad pero encuentran limitaciones para hacerlo.

Una línea alternativa de análisis sostiene que la liberalización comercial reduce la informalidad laboral. Bajo esta perspectiva, luego del cambio de política comercial algunas firmas encontrarán más rentable ingresar a la formalidad, abandonando las prácticas informales, y las firmas informales menos productivas serán forzadas a abandonar la industria (Fiess y Fugazza, 2008).

Varias son las razones que motivan el estudio de la relación causal entre los cambios en la política comercial y la probabilidad de ser un trabajador informal. En primer lugar, los datos disponibles indican que en el año 2009 más del 35\% de la fuerza laboral argentina trabajó en la informalidad, y el fenómeno se ha incrementado en el tiempo pasando de un promedio de $25 \%$ en la década del ochenta, a $33 \%$ en la del noventa y $42 \%$ en los últimos años ${ }^{2}$. Es decir, que la informalidad laboral es un fenómeno persistente en el mercado de trabajo local. En segundo lugar, constituye un aporte a la necesidad de comprender cómo los mercados laborales de los países en desarrollo ajustan ante reformas comerciales. Algunos trabajos han estudiado el impacto de la apertura comercial sobre los salarios en Argentina. Galiani y Porto (2008) encuentran que las tarifas industriales reducen el diferencial salarial por calificación de la

\footnotetext{
${ }^{2}$ Fuente: Socio-Economic Database for Latin America and the Caribbean (CEDLAS y Banco Mundial, 2010).
} 
industria y, dada la estructura sectorial de tarifas, la apertura comercial genera una reducción en dicho diferencial, mientras que los resultados de Galiani y Sanguinetti (2003) indican que la liberalización comercial sólo puede explicar una pequeña proporción del aumento en la desigualdad salarial durante los noventa. Por último, son pocos los trabajos que han examinado la relación empírica entre liberalización comercial y empleo informal. Esto en parte refleja la escasez de encuestas que contengan información suficiente para determinar la condición de informalidad de los trabajadores. En este sentido, la disponibilidad de datos para el caso de Argentina aparece como una oportunidad para explorar esta relación.

El trabajo se estructura de la siguiente manera. La Sección 2 presenta y analiza los trabajos más destacados y recientes que pueden encontrarse en la literatura sobre impacto de las reformas comerciales sobre la informalidad laboral. La Sección 3 se concentra en los aspectos conceptuales relevantes para el desarrollo de este estudio. En primer lugar, se presenta una discusión sobre las medidas de liberalización comercial disponibles y su pertinencia para el propósito del trabajo. En segundo lugar, se analizan las definiciones alternativas de informalidad laboral y sus posibilidades de implementación de acuerdo a la información disponible. En la Sección 4 se describen los datos que serán utilizados en el estudio y se exponen los elementos y relaciones claves para establecer una estrategia de identificación válida del efecto causal de las reformas comerciales sobre la informalidad laboral. Los resultados obtenidos se presentan en la Sección 5 mientras que la Sección 6 concluye con los comentarios finales.

\section{Revisión de la literatura}

Los estudios que analizan la relación empírica entre liberalización comercial e informalidad laboral son escasos y se limitan a la experiencia de ciertos países. Gran parte de la evidencia disponible en la literatura se refiere a los casos de Brasil, México, Colombia y Marruecos, países donde existen fuentes de información suficientes para realizar este tipo de estudio.

Goldberg y Pavcnik (2003) utilizan información proveniente de encuesta de hogares de Brasil y Colombia para analizar la relación existente entre los fenómenos de liberalización comercial e informalidad laboral en estos países durante las décadas del ochenta y noventa. Sus resultados no brindan evidencia de que las reformas comerciales hayan contribuido a la 
expansión de la informalidad. En el caso de Brasil no encuentran ningún tipo de relación entre estos dos fenómenos, mientras que para Colombia los resultados indican que las reducciones tarifarias están asociadas con un aumento en el empleo informal, pero sólo en el período previo a las reformas laborales y la magnitud de este efecto es pequeña. Las autoras desarrollan un modelo dinámico de salarios de eficiencia donde la apertura comercial genera un aumento en el costo marginal de contratar trabajadores reduciendo el tamaño óptimo de la planta formal de empleados. La magnitud de este efecto depende inversamente de la probabilidad de detectar actividades de “shirking” y esa probabilidad es inferior en presencia de normas laborales rígidas. Como resultado, el impacto de la apertura comercial sobre la informalidad será más fuerte antes de una reforma laboral que flexibilice las reglas de contratación y despido. Este resultado sugiere que las instituciones laborales tienen un rol importante en cómo las reformas comerciales afectan el empleo informal. En particular, cuando las firmas operan en mercados laborales rígidos es más probable que reaccionen mediante reducciones en el empleo formal ante la mayor competencia internacional.

Alemán-Castilla (2006) utiliza la experiencia del North American Free Trade Agreement (NAFTA) para analizar la relación entre informalidad laboral y apertura comercial en el caso de México para el período 1989-2002. Mediante un modelo dinámico de industrias con heterogeneidad de firmas, el autor concluye que la eliminación de las tarifas a las importaciones puede reducir la incidencia de la informalidad al ser más rentable para algunas firmas ingresar a la formalidad abandonando las prácticas informales, forzando a las firmas menos productivas a dejar la industria e induciendo a las firmas formales más productivas a participar del comercio. Las predicciones de este modelo son testeadas a partir de información sobre tarifas a las importaciones mexicanas y estadounidenses y datos provenientes de la Encuesta Nacional de Empleo Urbano. El autor encuentra que la reducción de tarifas mexicanas se asocia significativamente con menores niveles de informalidad laboral en el sector transable de la economía. Para una cierta reducción en las tarifas mexicanas, la caída en la informalidad es menor en aquellas industrias con altos niveles de penetración de importaciones y superior en aquellas donde la orientación hacia las exportaciones es mayor, dada una cierta reducción en las tarifas estadounidenses.

Ambos estudios implementan una estrategia de estimación en dos etapas. En primer lugar, estiman un modelo lineal de la probabilidad de empleo informal para cada año controlando 
por características de los trabajadores y variables indicadoras de la afiliación industrial de cada uno de ellos. Los coeficientes asociados a estas variables reciben el nombre de industry informality differentials y captan toda aquella parte de la variación en el empleo informal que no puede ser explicada por las características personales de los trabajadores pero sí por su afiliación industrial. Los industry informality differentialas son luego agrupados para todos los años y regresados en las variables de política comercial de cada industria mediante Mínimos Cuadrados Ponderados, corrigiendo los errores estándar por heterocedasticidad y correlación serial a nivel de industria. Este tipo de estrategia empírica tiene su origen en la década del ochenta con la literatura sobre diferenciales salariales (Dickens y Katz, 1986; Katz y Summers, 1989). La motivación para el desarrollo de un procedimiento en dos etapas se centró en aquel momento en la incorrecta determinación de los errores estándar estimados por Mínimos Cuadrados Ordinarios cuando la especificación del modelo incluía variables a nivel individual y variables agrupadas, lo que conducía a sobreestimar la significatividad estadística de estas últimas. Sin embargo, con posterioridad al desarrollo de esta técnica surgieron métodos econométricos sofisticados que permiten corregir por la correlación del término de error al interior de cada grupo. Dado esto, la estimación en dos etapas, separando las características individuales de aquellas agregadas (a nivel de industria en este caso), es indistinguible de la estimación de un único modelo que incorpore las variables a nivel individual y grupal. Por otro lado, existen características individuales que pueden presentar un alto grado de correlación a nivel de grupo. Por ejemplo, el nivel educativo es un atributo específico del individuo que tiende a ser similar entre aquellos trabajadores empleados en la misma industria de acuerdo a las características del proceso productivo. La inclusión del nivel educativo de los individuos en la primera etapa estaría generando el mismo problema que la metodología intenta resolver, mientras que un único modelo con regresores a nivel individual y grupal podría corregir por la correlación al interior de cada industria.

A partir de una estrategia empírica diferente, Boni, Gosh y Maloney (2007) estudian los flujos brutos de trabajadores para explicar el aumento en la informalidad en los mercados laborales metropolitanos de Brasil entre 1983 y 2002. Este período abarca dos ciclos económicos, diversos planes de estabilización macroeconómica, la apertura comercial y varios cambios en la legislación laboral de este país. Los movimientos seculares del nivel de flujo de trabajadores y su volatilidad sugieren que el aumento de la informalidad durante este período fue 
causado en gran medida por una caída en la tasa de obtención de empleo en el sector formal. El resto de la explicación descansa en la reforma constitucional de 1988 que contribuyó a aumentar los costos laborales y a reducir la flexibilidad del mercado de trabajo. Sólo una pequeña parte del aumento en la informalidad puede ser explicada por la apertura comercial. Para arribar a esta última conclusión, los autores replican la estrategia en dos etapas de Goldberg y Pavcnik (2003) para estimar el impacto de la apertura comercial sobre la informalidad laboral. Una característica interesante de este trabajo y crucial para la metodología empleada es el uso de la Pesquisa Mensal de Emprego, encuesta de empleo mensual realizada en las seis regiones metropolitanas más importantes de Brasil, que posee una estructura de panel rotativo, lo que permite monitorear al mismo individuo durante cuatro meses consecutivos.

En otro trabajo, Currie y Harrison (1997) analizan el impacto de las reformas comerciales sobre el empleo en las firmas manufactureras de Marruecos durante la década del ochenta. Si bien el estudio no analiza el impacto directo de la apertura comercial sobre la informalidad, ofrece algunas ideas acerca del rol de las políticas de protección sobre la composición de los mercados laborales. A partir de datos provenientes de firmas manufactureras con más de diez empleados, sus resultados sugieren que el empleo en la firma promedio no resultó afectado por la reducción de tarifas y la eliminación de cuotas a las importaciones. Sin embargo, las firmas exportadoras y aquellas industrias más afectadas por las reformas (textiles, alimentos e indumentaria) experimentaron una caída significativa en su nivel de empleo.

Fiess y Fugazza (2008) se encuentran entre los pocos estudios que analizan la relación empírica entre apertura comercial e informalidad laboral para un conjunto de países. Utilizando fuentes de datos alternativas ${ }^{3}$, encuentran que las correlaciones no condicionadas entre países respaldan la visión de que la liberalización comercial reduce la informalidad laboral, mientras que los resultados alcanzados a partir de datos de un panel de países indican lo contrario. El análisis de co-integración muestra que la apertura comercial se asocia a mayores niveles de producto y empleo informal para la mayoría de los países analizados. Los datos

\footnotetext{
${ }^{3}$ Por un lado, utilizando datos sobre empleo informal provenientes de la OIT, construyen un panel no balanceado para 32 países durante el período 1990-2004. En segundo lugar, recurriendo a las estimaciones de empleo informal presentadas por Schneider en el año 2007 que surgen de la combinación del Currency Demand Approach y el método DYMIMIC de Giles, obtienen una serie de tiempo para 110 países durante el período 2000-2004. Por último, a partir del enfoque macroeconómico de Kaufmann y Kaliberda que atribuye toda diferencia entre el crecimiento del consumo de electricidad y del PBI a cambios en el tamaño del sector informal, construyen un panel balanceado para 66 países durante el período 1990-2004 con datos provenientes del World Development Indicators y el FMI.
} 
macroeconómicos respaldan la visión tradicional de un aumento en la informalidad laboral a partir de la apertura comercial mientras que la evidencia obtenida a partir de microdatos sugiere lo contrario.

En resumen, los estudios empíricos no son concluyentes respecto a la relación entre los fenómenos de informalidad laboral y reformas comerciales. Los resultados difieren según el país considerado y la metodología de análisis empleada. Adicionalmente, los desarrollos teóricos han tenido el propósito de capturar cierta línea de pensamiento y presentar de un modo consistente y formal los hallazgos empíricos. Goldberg y Pavcnik (2003) desarrollan un modelo dinámico de salarios de eficiencia y muestran que la apertura comercial se asocia a mayores niveles de informalidad laboral. Sin embargo, las autoras reconocen que con modelos alternativos podrían obtener el resultado opuesto. A la misma conclusión puede arribarse adaptando el modelo desarrollado por Galiani y Porto (2008) quienes estudian la relación entre la liberalización comercial y los salarios. De acuerdo a este modelo, las tarifas determinan el tamaño de la "renta tarifaria” de las firmas del sector transables importador. Los sindicatos se apropian de parte de esta renta para asignarla entre los trabajadores no calificados de este sector, lo que resulta en un salario superior respecto al salario competitivo de los trabajadores no calificados del sector de bienes no transables y del sector transable exportador. La apertura comercial resultará, entonces, en una menor renta tarifaria y un menor poder de los sindicatos. Extendiendo este análisis a la informalidad laboral, la reducción de tarifas se asociaría a mayores niveles de informalidad en el sector transable importador. Contrariamente a estos resultados, Alemán-Castilla (2006) concluye, mediante un modelo dinámico de industrias con firmas heterogéneas, que la apertura comercial reduce la tasa de informalidad. Es decir, que la literatura ofrece argumentos teóricos diversos para explicar los resultados obtenidos a partir del análisis empírico. En cuanto a los datos, la disponibilidad de un panel de individuos representa una clara ventaja en términos de poder controlar por heterogeneidades no observadas a nivel individual, un factor que puede ser relevante para explicar la condición de informalidad de los trabajadores.

\section{Definición de variables relevantes}


Esta sección se focaliza en los aspectos conceptuales vinculados a la elección de una medida de liberalización comercial adecuada para el establecimiento de la relación causal de interés y de una definición de informalidad laboral compatible con los datos disponibles.

\subsection{Medida de liberalización comercial}

La política comercial de un país es un evento difícil de captar empíricamente y de una manera adecuada a través de una medida o indicador. El uso de las importaciones, exportaciones o ambas como proxies de la apertura comercial presenta el problema de su determinación simultánea con las variables que habitualmente son objeto del análisis, por ejemplo, los salarios (Goldberg y Pavcnik, 2004).

Las barreras no arancelarias, como las licencias de importación y cuotas, constituyen una alternativa al uso de los flujos comerciales, aunque su definición práctica presenta algunas limitaciones. Usualmente, este tipo de medidas se captan mediante una razón de cobertura para algún nivel de agregación de la industria. La razón de cobertura mide la participación de las importaciones en cierta industria sujeta a barreras no arancelarias. Sin embargo, este indicador no captura la verdadera restricción de la medida ya que, por ejemplo, una industria puede registrar el mismo valor de razón de cobertura en dos años diferentes aunque las barreras no arancelarias pueden haber sido más restrictivas en alguno de esos años por diferentes condiciones de demanda (Goldberg y Pavcnik, 2006). Por lo tanto, la comparación entre industrias y en el tiempo es problemática en este caso.

Las tarifas aduaneras, en cambio, son una expresión de la política comercial de un país que es fácil de medir y es comparable en el tiempo. Las tarifas representan un impuesto advalorem sobre los bienes importados, es decir, son una forma de protección comercial basada en el precio. Como tal, es más transparente, relativamente más fácil de medir, comparable entre industrias y en el tiempo y su magnitud refleja la verdadera restricción de la medida (Goldberg y Pavcnik, 2003; Goldberg y Pavcnik, 2006). Y aún cuando el país emplee barreras no arancelarias, su razón de cobertura y los cambios en el tiempo tienden a estar positivamente correlacionados con las tarifas. Galiani y Porto (2008) encuentran que la correlación entre las tarifas y barreras no arancelarias en el caso de Argentina es positiva y baja (alrededor de 0.03). Esto significa, por un lado, que la omisión de las medidas no arancelarias de protección 
comercial en un modelo econométrico sería menos problemática en términos de la consistencia de los estimadores ${ }^{4}$. Por otro lado, que la correlación sea positiva garantiza que una reducción tarifaria no sea acompañada de un aumento simultáneo en las barreras no arancelarias, anulando el efecto de la primera medida. Entonces, si bien el impacto de la política comercial sobre el empleo informal estará sobreestimado, éste representará el efecto conjunto de la política comercial y no sólo de las tarifas.

Más allá de estas ventajas en el uso de las tarifas aduaneras para captar la política comercial, pueden presentarse algunos problemas de medición. El más importante está vinculado al nivel de agregación de los datos sobre tarifas y sobre la variable de interés. Los gobiernos nacionales generalmente establecen las tarifas aduaneras con niveles muy amplios de desagregación. Esto genera la necesidad de agregar esta información de modo que coincida con el grado de apertura industrial para el cual está expresada la variable sobre la cual se intenta medir el impacto de la política comercial. Este procedimiento puede generar errores de medición en las tarifas a nivel de industria (Goldberg y Pavcnik, 2006). Por otro lado, las tarifas aduaneras sobre bienes finales no captan verdaderamente la protección que recibe cada industria al no tener en cuenta la protección indirecta dada por las tarifas sobre los bienes intermedios. El efecto completo podría captarse mediante la construcción de tarifas efectivas (Goldberg y Pavcnik, 2003). Sin embargo, las tarifas efectivas no están disponibles en el caso de Argentina y su construcción presentaría problemas adicionales de medición y compatibilidad.

A pesar de esto, las características de los episodios de apertura comercial para el caso argentino determinan que el uso de las tarifas resulte en ventajas adicionales vinculadas a la estrategia de identificación del efecto de interés. Como se verá en secciones siguientes, las tarifas aduaneras han variado notablemente entre industrias durante los episodios de liberalización. Esto significa que la apertura comercial no sólo redujo el nivel de tarifas sino que también alteró la estructura de protección entre industrias: aquellas que tradicionalmente recibieron alta protección, experimentaron los mayores recortes, mientras que las industrias con bajas tarifas enfrentaron reducciones menores. Este recorte diferencial de tarifas entre industrias es una fuente

\footnotetext{
${ }^{4}$ La existencia de una correlación no nula entre las tarifas y las barreras no arancelarias resulta en estimadores inconsistentes del efecto de la política comercial, captada mediante las tarifas, sobre la probabilidad de ser un trabajador informal y el tamaño de la inconsistencia dependerá directamente de la correlación entre estas variables.
} 
de variabilidad que puede explotarse para identificar el impacto de la política comercial sobre la probabilidad de ser un trabajador informal.

Las tarifas a las importaciones son, entonces, la manifestación de la política comercial con mayores ventajas en la tarea de medición y en la determinación empírica de la relación de interés. Es por ello que en este trabajo se utilizarán datos sobre las tarifas a las importaciones aplicadas en las distintas industrias del sector manufacturero durante el período 1980-20015 . Estos datos provienen del trabajo de Galiani y Porto (2008) y en la Sección 4 se describe de manera detallada su definición y construcción.

\subsection{Definición de informalidad laboral}

La informalidad laboral es un término ambiguo desde el punto de vista teórico y difícil de hacer operativo empíricamente. En la literatura pueden encontrarse al menos dos definiciones de informalidad laboral que hacen referencia a distintos fenómenos del mercado de trabajo. Por un lado, la definición "productiva” se basa en el tipo de firma y de empleo, mientras que la definición "legalista” hace referencia al cumplimiento de ciertas normas laborales (Gasparini y Tornarolli, 2007).

Bajo la noción “productiva” y de acuerdo a la definición de la Organización Internacional del Trabajo (1991), las firmas informales son aquellas que poseen una baja dotación de capital, que utilizan tecnologías primitivas, emplean trabajo no calificado y, por lo tanto, tienen baja productividad. Teniendo en cuenta que la dotación de capital no es habitualmente reportada en las encuestas, que la definición de tecnología primitiva es difícil de precisar y la productividad no es directamente observable, resulta difícil determinar esta noción de informalidad laboral en la práctica. Dadas estas restricciones informativas, la manera en que normalmente se hace operativa esta definición es recurriendo a datos sobre el tipo de empleo, tipo de firma y calificación de los trabajadores.

Alternativamente, la definición "legalista” califica como informales a aquellas firmas que no cumplen con las normativas vinculadas a contratos, impuestos y regulaciones laborales y sus empleados no poseen protección laboral o beneficios sociales vinculados al empleo. La dificultad de implementación en este caso tiene que ver con la posibilidad de comparación entre países. Por

\footnotetext{
${ }^{5}$ La extensión del período de análisis depende directamente de la disponibilidad de información sobre tarifas a las importaciones.
} 
un lado, la protección laboral y seguridad social comprenden numerosas dimensiones que difieren entre países, dependiendo del diseño y funcionamiento de sus sistemas ${ }^{6}$. Por el otro, las encuestas de hogares difieren en la cobertura dada a estos temas. Por ejemplo, algunas encuestas preguntan sobre la modalidad de trabajo mediante contrato mientras que otras no hacen referencia a este punto. Asimismo, el tipo de pregunta formulada para captar cierto tema puede ser muy diferente limitando las posibilidades de comparación (Gasparini y Tornarolli, 2007).

El derecho a percibir una jubilación a partir del momento de retiro es el beneficio de la seguridad social más frecuentemente preguntado en las encuestas de hogares de países de América Latina. Esto ha determinado que en la práctica se defina como un trabajador informal a aquel que no posee este derecho vinculado a su empleo (Gasparini y Tornarolli, 2007).

Dadas las limitaciones para abordar empíricamente la noción “productiva” de informalidad y que sólo se trabajará con el caso argentino, en este trabajo se recurrirá a la noción “legalista” de informalidad laboral, definiendo a un trabajador como informal cuando no posea el derecho a percibir una jubilación al momento de su retiro.

Más allá de la definición teórica y tratamiento empírico del concepto de informalidad laboral, existe un aspecto controvertido de este fenómeno que tiene que ver con la habitual asociación a menores niveles de salarios y a condiciones laborales inferiores. Muchos estudios han encontrado que trabajadores con las mismas características observables ganan menos cuando son empleados informales ${ }^{7}$. Sin embargo, esta relación negativa no puede interpretarse en un sentido causal y las comparaciones de bienestar derivadas de este tipo de resultados pueden conducir a conclusiones equivocadas. Un trabajador informal difiere de uno formal en otras dimensiones más allá del salario recibido. En un mercado sin distorsiones los trabajadores igualarían la utilidad derivada de cada empleo, es decir, el conjunto de beneficios, no sólo los salarios (Maloney, 2003). Si el salario fuese el mismo entre dos empleos donde uno de ellos es formal y el otro informal, el trabajo informal podría ser considerado inferior porque no permite acceder a los beneficios de la seguridad social. Pero, por otro lado, para algunos trabajadores podría ser más valioso dado que la informalidad usualmente está vinculada a una mayor

\footnotetext{
${ }^{6}$ Las dimensiones comprendidas por la protección laboral incluyen: contrato de trabajo, indemnización por despido, aviso anticipado de despido, derecho de sindicalización, seguro por accidente de trabajo, vacaciones pagas, límite de horas de trabajo. Los beneficios de la seguridad social incluyen jubilación, seguro de salud y otros seguros y beneficios (Gasparini y Tornarolli, 2007).

7 Gasparini y Tornarolli (2007) para el caso de América Latina; Ulyssea (2006) para Brasil; Marcouiller, Ruiz de Castilla y Woodruff (1997) para Perú y El Salvador.
} 
flexibilidad y esa puede ser considerada una amenidad. Asimismo, un mayor salario en el empleo formal puede estar compensando a esos trabajadores por los impuestos pagados que sostienen la provisión de bienes y servicios públicos de la cual los trabajadores informales no pueden ser excluidos. Por todo esto, la informalidad no necesariamente es una opción inferior.

Vinculado a esto, aparece la doble perspectiva de la informalidad laboral. Por un lado, como exclusión de los beneficios estipulados por el Estado y, por el otro, como escape o elección del propio trabajador. Muchos trabajadores, mediante un análisis implícito de costo-beneficio sobre la decisión de cruzar el margen hacia la formalidad, pueden elegir no pertenecer a las instituciones formales privilegiando la flexibilidad y el mayor consumo presente (Perry et al., 2007). Para el caso del Gran Buenos Aires, sin embargo, esta doble perspectiva no parece adecuada para describir la condición de informalidad de los trabajadores. Existe evidencia que indica que la mayor parte de los trabajadores informales está en dicha situación porque tiene restricciones para acceder a un trabajo formal (Waisgrais y Sarabia, 2008). Estos trabajadores tienden a estar insatisfechos con sus empleos más allá de la categoría ocupacional a la que pertenezcan. De aquí se desprende que los trabajadores informales desearían ingresar a la formalidad pero encuentran limitaciones para hacerlo.

\section{Reformas comerciales e informalidad laboral}

En esta sección se describen, en primer lugar, los datos sobre tarifas a las importaciones y sobre fuerza laboral que serán utilizados en el estudio. En segundo lugar, se presentan los elementos y relaciones claves para establecer una estrategia de identificación válida del efecto causal de las reformas comerciales sobre la informalidad laboral.

\subsection{Datos sobre tarifas a las importaciones}

Siguiendo las conclusiones del apartado 3.1, las tarifas a las importaciones aplicadas sobre cada industria del sector manufacturero será la medida utilizada para captar la política comercial y su impacto sobre la informalidad laboral. Los datos sobre tarifas ad-valorem provienen del trabajo de Galiani y Porto (2008). Las mismas fueron construidas a partir de información de la Guía Práctica del Exportador e Importador, una publicación con datos sobre 
tarifas a las importaciones con el mayor nivel de desagregación de la Nomenclatura Arancelaria y Derechos de Importación (NADI) y del Sistema Armonizado, según el período considerado ${ }^{8}$.

Dado que a lo largo del período analizado existieron distintos arreglos institucionales (como la adopción del Mercosur durante los noventa) y se aplicaron diferentes medidas de política comercial, los autores construyen, utilizando la tarifa vigente a la mitad de cada año, una medida hasta el año 1991 que comprende la tarifa más la tasa estadística ${ }^{9}$, y desde el año 1992 la medida se compone de la tarifa extra-Mercosur, la tasa estadística, un derecho de importación mínimo específico ${ }^{10}$ y un factor de convergencia en el año $2001^{11}$.

Para que la información sobre tarifas sea compatible con la apertura industrial que posee la Encuesta Permanente de Hogares (EPH) de Argentina ${ }^{12}$ y que se basa en la clasificación ISIC (International Standard Industrial Classification), los autores agregan las alícuotas hasta obtener una medida compatible con la clasificación ISIC a 3 dígitos. Para esto, siguen un proceso iterativo donde se computa la tarifa mediana de las subcategorías comprendidas en cada categoría principal de los datos sobre tarifas, donde previamente se buscó la correspondencia entre cada una de ellas y las categorías de la clasificación ISIC. El Instituto de Estadísticas y Censos de Argentina (INDEC) empleó hasta el año 1991 la clasificación ISIC revisión 2 y desde entonces, la clasificación ISIC revisión 3. Esto resulta en dos series de tarifas dependiendo de la clasificación ISIC con la cual fueron compatibilizadas y es por esta razón que los autores finalmente construyen una serie final que abarca todo el período y que combina ambas clasificaciones industriales. Para esto, siguen una nomenclatura intermedia elaborada por el Banco Mundial. Siguiendo a Galiani y Porto (2008), las tarifas son finalmente ajustadas para tener en cuenta el proceso progresivo de ajuste del arancel aplicado a las importaciones procedentes de los países miembros del Mercosur, de acuerdo a lo establecido en el Tratado de

\footnotetext{
${ }^{8}$ La NADI tuvo vigencia hasta el año 1992 cuando fue reemplazada por la Nomenclatura del Comercio Exterior (NCE). En 1993 se adoptó el Sistema Armonizado de Designación y Codificación de Mercancías. Con posterioridad, los estados parte del Mercosur adoptaron una nomenclatura común basada en la nomenclatura internacional bajo la denominación de Nomenclatura Común del Mercosur (NCM).

${ }^{9}$ La tasa estadística es una carga ad-valorem adicional aplicada por el gobierno sobre ciertos bienes para financiar la recolección de datos estadísticos.

${ }^{10}$ El derecho de importación mínimo específico es una medida anti-dumping aplicada sobre ciertos bienes importados.

${ }^{11}$ El factor de convergencia fue establecido por ley en junio del año 2001. Fue calculado como $f c=1-\frac{1+e}{2}$ donde $e$ es el precio en dólares de 1 euro.

${ }^{12}$ La Encuesta Permanente de Hogares de Argentina es llevada a cabo por el Instituto Nacional de Estadísticas y Censos y es la fuente de microdatos que se utilizará en este trabajo. Ver apartado siguiente.
} 
Asunción del año 1991. Esta serie de tarifas a las importaciones proveniente de los datos de Galiani y Porto (2008) fue luego combinada con las bases correspondientes a la EPH para el período 1980-2001 obteniendo entonces información sobre protección comercial y microdatos para 24 industrias del sector manufacturero en el Gran Buenos Aires ${ }^{13}$.

En el Cuadro 4 del Anexo Estadístico se presentan, para cada uno de los años considerados, las estadísticas descriptivas de la medida de tarifas construida por Galiani y Porto (2008) y combinada con las EPH del período 1980-2001 para el Gran Buenos Aires. La evolución temporal muestra que la tarifa promedio cayó un 54\% entre los años 1980 y 2000. El Gráfico 1 a continuación permite observar los cambios en la política comercial a partir de la distribución de la medida de tarifa para cada año. De la observación de las distribuciones es posible distinguir tres etapas en la política comercial de acuerdo a los niveles de tarifas aplicados. El año 1980, caracterizado por el nivel más alto de protección de todo el período considerado, con una tarifa promedio cercana al 40\%, e industrias con un nivel de protección de hasta el 55\%. Entre 1985 y 1989 la tarifa promedio fue 10 puntos porcentuales inferior y toda la distribución se desplazó hacia abajo: con excepción del año 1989, el percentil 75 estuvo por debajo del percentil 25 del año 1980. Si bien existió un proceso continuo de reducción de tarifas, este fue un período caracterizado por el uso de barreras no arancelarias al comercio que comenzaron a ser eliminadas hacia el año $1988^{14}$. Se destaca también la reversión de este proceso de reducción de tarifas hacia el año 1989, coincidiendo con la crisis hiperinflacionaria. A partir del año 1990 Argentina implementó un amplio programa de liberalización comercial. La reducción unilateral de tarifas fue acompañada de la liberalización del comercio regional mediante el establecimiento del Mercado Común del Sur (Mercosur) entre Argentina, Brasil, Paraguay y Uruguay en el año 1991. A través de este acuerdo comercial se dispuso eliminar los impuestos a las importaciones entre los países miembros y se estableció un programa de reducciones progresivas para alcanzar este objetivo. También se acordó una tarifa común para la importación de bienes provenientes de los países extra-región. De acuerdo a lo establecido por el Tratado de Asunción del año 1991 mediante el cual los Estados Parte deciden crear el Mercosur,

\footnotetext{
${ }^{13}$ El Cuadro 3 en el Anexo Estadístico presenta la definición de cada una de las 24 industrias.

${ }^{14} \mathrm{Si}$ bien la construcción de una medida que capte la protección no arancelaria es difícil de obtener, los registros históricos indican que esta fue una etapa donde el uso de este tipo de medidas se reinstaló para luego ser eliminado a inicios de la década del noventa como requisito para iniciar las negociaciones del Mercosur (Galiani y Porto, 2008).
} 
el Mercado Común debería estar conformado para el 31 de diciembre de $1994^{15}$. En esta etapa la tarifa promedio descendió otros 10 puntos porcentuales y también se verificó una menor variabilidad de tarifas entre sectores. Por último, en el año 2001 se produjo un aumento en el nivel de tarifas, posiblemente explicado por un intento de prevenir la crisis fiscal (Galiani y Porto, 2008).

\section{Gráfico 1}

Distribución de la tarifa mediana, industrias definidas según ISIC a 3 dígitos

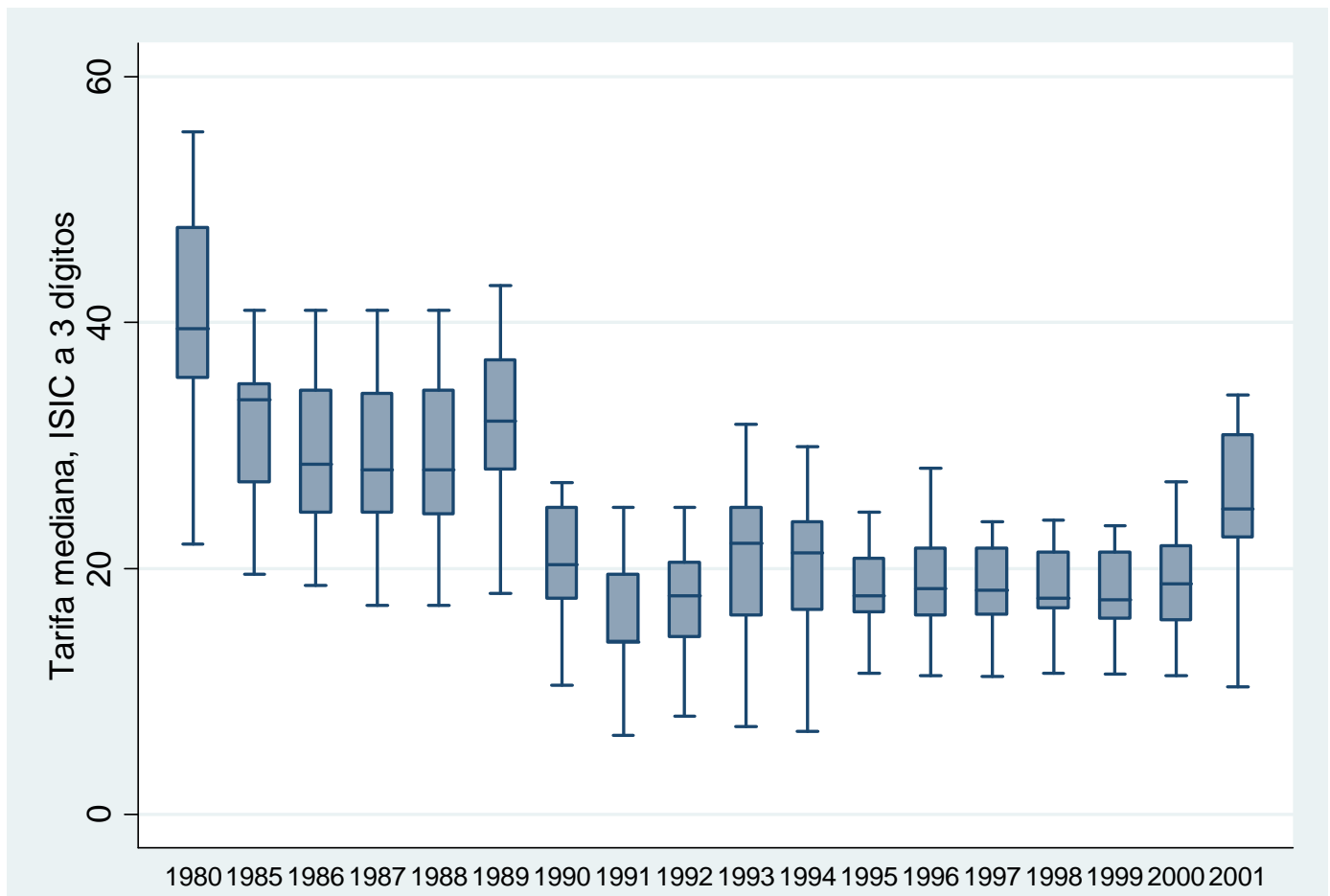

Fuente: Elaboración propia en base a EPH y Galiani y Porto (2008).

Nota: Los extremos de los box corresponden al percentil 25 y 75, respectivamente; la línea dentro de cada box representa el valor mediano de la distribución de tarifas; cada sector está ponderado por el nivel de empleo.

El Gráfico 2 muestra el cambio en el nivel de protección de cada industria del sector manufacturero entre los años 1980 y 2000. En el panel izquierdo del gráfico se observa que para todas las industrias se verifica una reducción de tarifas entre los años mencionados y un cambio en la estructura de protección. Es decir, la apertura comercial no impactó de igual manera en

\footnotetext{
${ }^{15}$ El período de tiempo transcurrido entre el año 1991 y el 31 de diciembre de 1994 se considera una etapa de transición o adecuación durante la cual los Estados Parte debían ajustar sus tarifas de acuerdo a lo establecido en el Tratado de Asunción.
} 
todas ellas. Más específicamente, aquellas industrias con mayor nivel inicial de tarifas experimentaron los mayores recortes (fabricación de prendas de vestir, fabricación de productos de la refinación del petróleo y combustible nuclear, fabricación de vehículos automotores, remolques y semirremolques), mientras que las que recibían un menor nivel de protección enfrentaron cambios menores (elaboración de productos alimenticios, elaboración de bebidas). Esto puede verse en el panel derecho del gráfico.

\section{Gráfico 2}

\section{Cambio en el nivel de protección de cada industria}
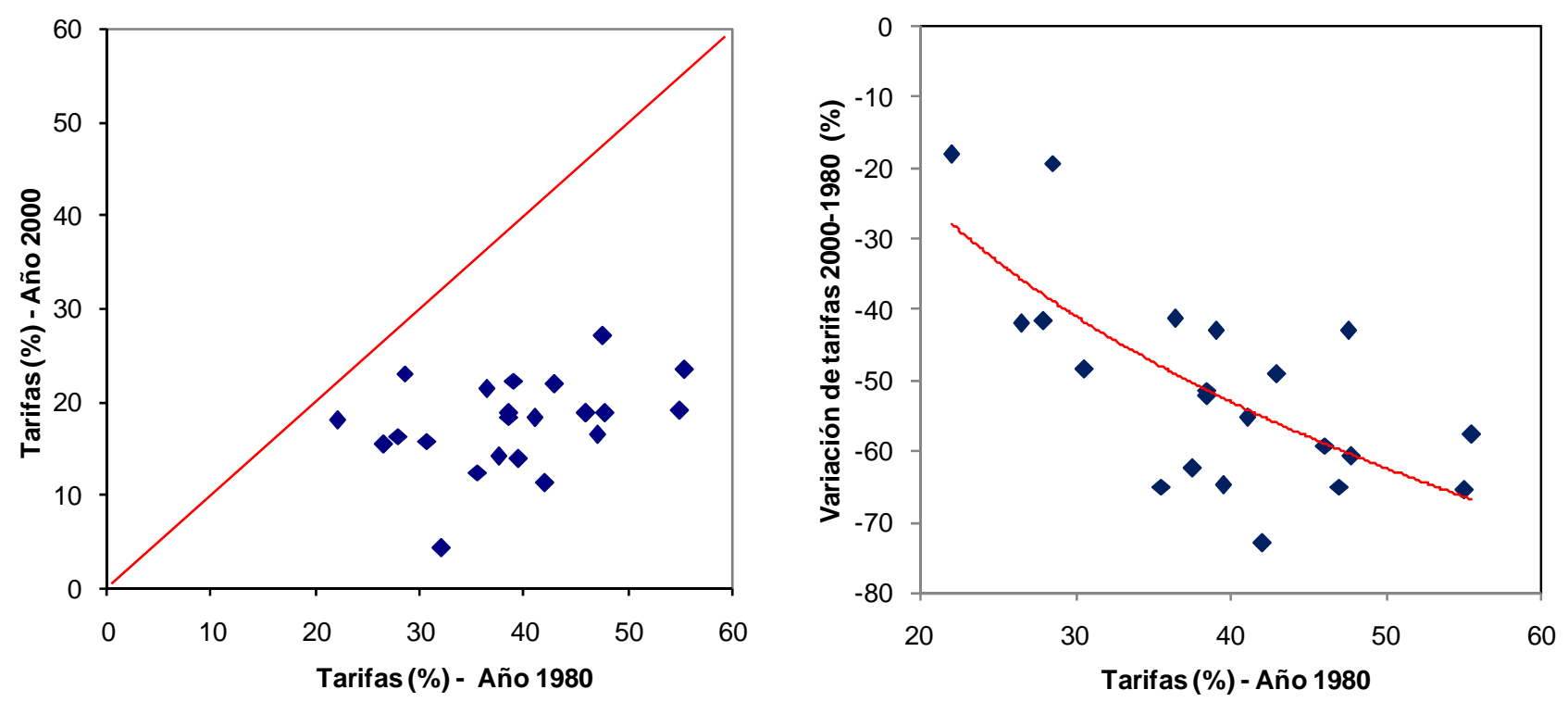

Fuente: Elaboración propia en base a EPH y Galiani y Porto (2008).

Como se verá en secciones siguientes, este recorte diferencial de tarifas entre industrias será clave para identificar el impacto de la liberalización comercial sobre la informalidad laboral.

\subsection{Datos sobre fuerza laboral}

Los microdatos sobre características de los trabajadores y sus hogares provienen de la Encuesta Permanente de Hogares, llevada adelante por el Instituto Nacional de Estadísticas y Censos desde el año 1974. 
Hasta el año 1991 la cobertura de la encuesta se limitó al aglomerado del Gran Buenos Aires, entre los años 1992 y 1997 se extendió a las 15 principales ciudades y desde entonces se ha encuestado a los 28 mayores aglomerados urbanos, extendiéndose luego a 31.

Dados los cambios en la cobertura geográfica de la encuesta a lo largo del tiempo, se trabajará sólo con el aglomerado del Gran Buenos Aires, pudiendo entonces extender el período de análisis a los años anteriores a 1992. Si bien esta decisión implica perder observaciones a partir de ese año, el aglomerado del Gran Buenos Aires representa, en promedio, el 72\% de la población total encuestada durante el período 1992-1997 y 53\% en el período 1998-2001. Asimismo, este aglomerado ha registrado a lo largo de los años la mayor participación de la actividad industrial respecto a las restantes regiones encuestadas, promediando 20\%. La limitación de datos disponibles sobre características laborales de los individuos en las encuestas previas a 1980 determinó que el período a considerar sea el comprendido entre los años 1980 y $2001^{16}$. Durante este período la encuesta fue llevada a cabo dos veces al año, en los meses de mayo y octubre, recibiendo el nombre de EPH-Puntual. El Cuadro 5 presenta información sobre las bases utilizadas y su tamaño ${ }^{17}$.

En el Cuadro 6 del Anexo Estadístico se muestra la caracterización de los trabajadores formales e informales del sector manufacturero del Gran Buenos Aires de acuerdo a la información proveniente de las EPH y para los años seleccionados. Se consideran individuos de entre 15 y 65 años de edad, empleados en el sector manufacturero del Gran Buenos Aires y que son asalariados ${ }^{18}$.

Los resultados indican que aquellos trabajadores informales de las industrias manufactureras han percibido un salario horario promedio (a precios del año 1999) persistentemente inferior al recibido por los trabajadores formales. Lo mismo ocurre con las horas semanales de trabajo. En este caso se observa una ampliación de la brecha desde el año 1992, cuando alcanzó el mínimo de 1.27 horas semanales de trabajo, hasta el 2001 cuando los trabajadores formales trabajaron 8 horas semanales más respecto a los informales.

Los trabajadores informales también se caracterizan por contar con una mayor proporción de mujeres respecto a los empleados formales, por tener un menor promedio de edad y una

\footnotetext{
${ }^{16}$ Los años incluidos en el análisis son 1980 y desde 1985 hasta 2001.

${ }^{17}$ La reducción en el tiempo del tamaño de las bases se explica por la pérdida de participación del sector de manufacturas en la población de ocupados.

${ }^{18}$ La EPH sólo pregunta sobre el derecho a recibir una jubilación al momento del retiro entre aquellos individuos asalariados.
} 
menor proporción de individuos casados y jefes de hogar. El número de niños menores a 15 años tiende a ser superior en los hogares de individuos empleados en condiciones de informalidad, mientras que el ingreso por adulto equivalente, expresado a precios del año 1999, siempre ha sido inferior. Si se considera al cónyuge del jefe de hogar un trabajador secundario, se encuentra que, en concordancia con la hipótesis de Galiani y Weinschelbaum (2006), los trabajadores secundarios tienen mayor participación entre los empleados informales.

En cuanto a los niveles educativos, tanto el grupo de trabajadores formales como informales, se caracterizan por tener una mayor proporción de individuos no calificados, aunque esta es superior entre los empleados informales. Por último, el 90\% de los trabajadores formales está empleado en firmas grandes mientras que ese porcentaje sólo asciende al 55\% entre los informales.

De estas diferencias en la composición demográfica de los trabajadores según su condición de informalidad se desprende la importancia de controlar por características individuales de los trabajadores y de su hogar en el análisis empírico.

\subsection{Reformas comerciales e informalidad laboral: evidencia preliminar}

El Gráfico 3 muestra la evolución en el tiempo del promedio de tarifas de todas las industrias, ponderado por el nivel de empleo de cada una de ellas, y de la tasa de informalidad laboral.

El gráfico permite distinguir las etapas antes descriptas en la evolución de la política comercial: un período inicial de alta protección, seguido de un proceso de liberalización y estancamiento de tarifas durante los ochenta con una reversión hacia el final de la década y, por último, un nuevo proceso de apertura en los noventa.

La tasa de informalidad laboral, en cambio, tuvo una evolución creciente a lo largo de todo el período, mostrando un aumento de más del 100\% entre los años 1980 y 2001. Mientras que el mayor incremento se dio en las primeras dos etapas, durante los noventa continuó la tendencia creciente aunque a un menor ritmo. Una particularidad interesante en la trayectoria de la tasa de informalidad es la reducción que mostró entre el año 1991 y 1994. En este último año, 
considerado como el más importante en término de reformas laborales ${ }^{19}$, la tasa de informalidad comenzó a crecer nuevamente, alcanzando picos de 32.4\% (año 1996) y 33.5\% (año 1999) ${ }^{20}$.

Si se compara la evolución de la tasa de informalidad en el sector de manufacturas con la registrada en el sector de bienes no transables ${ }^{21}$, se encuentra una tendencia similar y un mayor nivel en el segundo caso, con una muy baja variabilidad en la discrepancia entre ambos sectores. Esta similar evolución de la tasa de informalidad en el sector de manufacturas y de bienes no transables podría sugerir que los cambios en las tarifas aduaneras no fueron relevantes para explicar estas tendencias o que si lo fueron, su efecto fue poco importante en magnitud. Sin embargo, el sector de bienes no transables puede resultar indirectamente afectado por el cambio en las tarifas, registrando un cambio en su tasa de informalidad en el mismo sentido que el experimentado por el sector de manufacturas. Por ejemplo, ante un episodio de apertura comercial las firmas manufactureras pueden reducir costos recurriendo, entre otras estrategias, a la eliminación de los beneficios jubilatorios de sus empleados y/o al despido de parte de ellos que luego pueden ser incorporados como empleados informales por otras firmas de la misma industria, por firmas de otras industrias o por el sector de bienes no transables. Es importante destacar que este trabajo analizará los cambios en la tasa de informalidad al interior del sector manufacturero y, por lo tanto, no se estarán considerando los movimientos de trabajadores desde este sector hacia el de bienes no transables. Este punto cobra relevancia si se tiene en cuenta la caída en la participación del sector de manufacturas a lo largo del tiempo. Sin embargo, el trabajo no estará evaluando los flujos de trabajadores sino que se concentrará en los movimientos desde la formalidad hacia la informalidad al interior de cada industria de este sector. Es importante notar que a partir de un panel de individuos sería posible observar y analizar los movimientos de trabajadores entre sectores de la economía, en particular, los flujos entre los sectores de manufacturas y de bienes no transables.

\footnotetext{
19 De acuerdo a Torre y Gerchunoff (1999), hacia principios de 1994 los avances del gobierno en torno al objetivo de flexibilización laboral habían sido escasos y poco efectivos. Fue entonces que se ingresó en un proceso más gradualista y concertado con los sindicatos y empresarios que permitió destrabar la marcha de la flexibilización a través de la elaboración de varios proyectos de ley que luego se tradujeron en cambios efectivos: la proporción del empleo asalariado cubierto por modalidades flexibles de contratación se incrementó desde $6.3 \%$ en 1995 a $17 \%$ en 1997 . A pesar de esto, el sistema de relaciones laborales fue el ámbito donde con más dificultad y menor alcance penetraron las medidas de liberalización promovidas por el gobierno en la década del noventa.

${ }^{20}$ El registro de estos valores coincide temporalmente con sucesos de crisis financieras externas que repercutieron en la economía doméstica.

${ }^{21}$ La tasa de informalidad en el sector de bienes no transables se computó sin incluir al sector público.
} 


\section{Gráfico 3}

Informalidad laboral y tarifas a las importaciones: promedio para todas las industrias

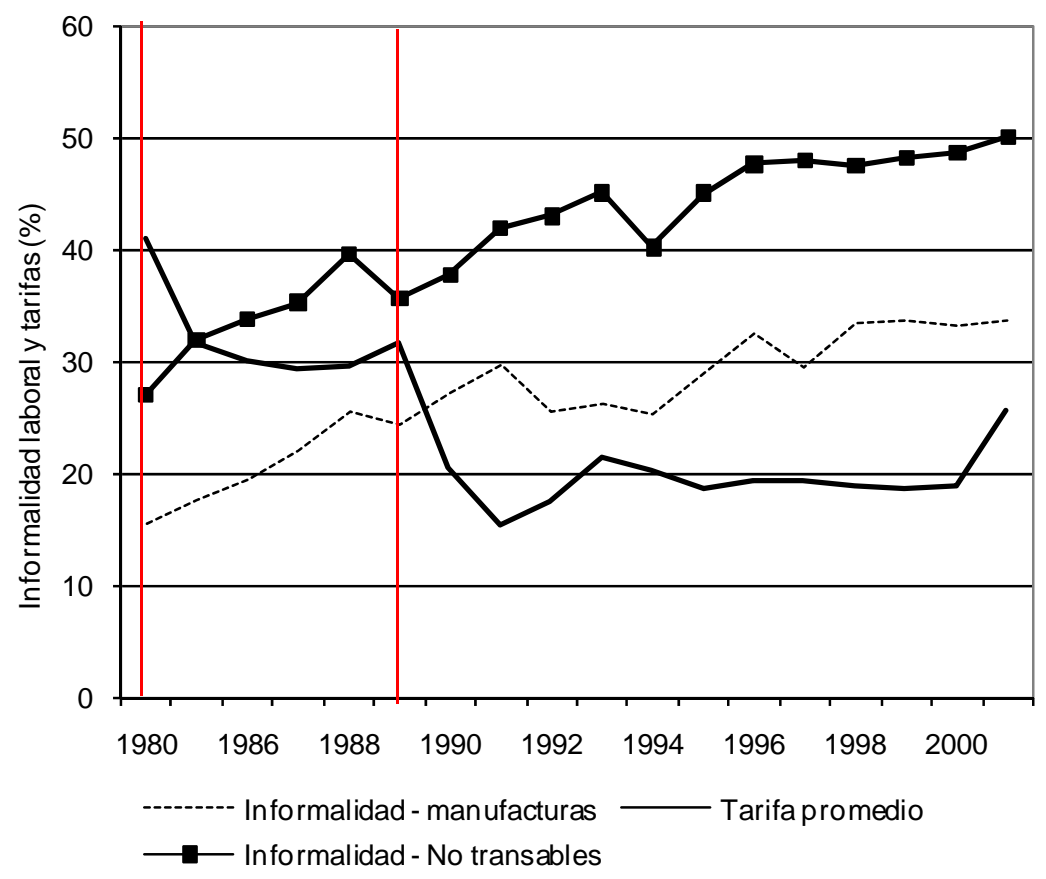

Fuente: Elaboración propia en base a EPH y Galiani y Porto (2008).

De esta primera aproximación surge que existe una correlación negativa (-0.74) entre las tarifas a las importaciones y la informalidad laboral a lo largo del período analizado o, equivalentemente, una correlación positiva entre los eventos de liberalización comercial e informalidad. Es decir, que la apertura comercial ha sido acompañada de incrementos en la tasa de informalidad en el sector manufacturero. Sin embargo, de este primer resultado no se puede inferir que exista una relación causal entre los fenómenos analizados. La identificación del efecto causal de los episodios de liberalización comercial sobre la informalidad requiere de una estrategia válida que permita aislar el impacto de la política comercial de otros factores. Más específicamente, la política comercial es el resultado de un proceso político y, por lo tanto, es una variable endógena cuando se modela la probabilidad de ser informal. El desafío será, entonces, lograr separar el impacto de la política comercial de otros factores, principalmente de política económica, como fueron, por un lado, los cambios simultáneos a la apertura comercial la reforma monetaria, las privatizaciones y desregulación de los mercados, incluyendo el laboral, 
durante la década del noventa (Cruces y Gasparini, 2008)- y, por el otro, la reacción de las industrias ante el ciclo económico.

El Gráfico 4 en el Anexo Estadístico muestra esta misma relación para cada una de las 24 industrias del sector manufacturero. Si bien la evolución de las tarifas a las importaciones es muy similar en todos los casos mostrando una importante reducción entre los años 1990 y 1991, la trayectoria de la informalidad laboral se comporta de manera diferente de acuerdo a la industria considerada. Por ejemplo, la reducción de tarifas se asocia con un aumento en la informalidad laboral en la industria de fabricación de muebles, mientras que en la de fabricación de maquinarias ese cambio no es igual de evidente.

La estrategia de identificación del impacto de la apertura comercial sobre la informalidad laboral se basará en la combinación de datos sobre las tarifas a las importaciones que se aplicaron en las distintas industrias del sector manufacturero y la tasa de informalidad en estas industrias del Gran Buenos Aires durante el período que se extiende desde el año 1980 hasta el año 2001.

Como se mostró en el Gráfico 2, la liberalización comercial no sólo redujo las tarifas sino que también alteró la estructura de protección entre industrias. Es decir, la naturaleza de las reformas comerciales durante este período fue tal que su impacto sobre la informalidad laboral puede ser identificado a partir de la variabilidad a nivel de industria de la política comercial. Esto es, el cambio diferencial de tarifas entre industrias es la fuente de variabilidad que se explotará para identificar el efecto deseado. La estrategia se apoya, entonces, en la premisa de que la movilidad de trabajadores desde la formalidad hacia la informalidad fue superior al interior de cada industria respecto a la movilidad entre industrias.

Esto puede ser respaldado mediante el análisis de la descomposición del cambio en el tiempo de la tasa de informalidad en cambios que se dieron al interior de cada industria (efecto within) y cambios que tuvieron lugar entre industrias (efecto between). El cambio en la tasa de informalidad entre los años $2001\left(t_{1}\right)$ y $1980\left(t_{0}\right)$ puede descomponerse de la siguiente manera (Goldberg y Pavcnik, 2003):

$$
\Delta_{t} I=\sum_{j} \Delta_{t} i_{j} \theta_{j}^{E}+\sum_{j} \Delta_{t} E_{j} \theta_{j}^{I}
$$


Donde $I$ representa la tasa de informalidad del sector manufacturero, $i_{j}$ y $E_{j}$ son la tasa de informalidad y el nivel de empleo en la industria $j$, respectivamente, y los parámetros $\theta_{j}^{E}$ y $\theta_{j}^{I}$ se computan como:

$$
\begin{aligned}
& \theta_{j}^{I}=\frac{1}{2}\left(i_{j, t 0}+i_{j, t 1}\right) \\
& \theta_{j}^{E}=\frac{1}{2}\left(E_{j, t 0}+E_{j, t 1}\right)
\end{aligned}
$$

El primer componente de la expresión es el cambio en la tasa de informalidad laboral que se explica por movimientos desde la formalidad hacia la informalidad al interior de cada industria y el segundo, el cambio en la tasa de informalidad que se explica por movimiento de trabajadores entre industrias.

El Cuadro 7 en el Anexo Estadístico presenta los resultados de esta descomposición. El cambio en la tasa de informalidad del sector manufacturero entre los años 1980 y 2001 fue de 18 puntos porcentuales (en el año 1980 esta tasa fue del 16\% y alcanzó el 34\% en el año 2001). Prácticamente la totalidad del cambio (99.7\%) se explica por el efecto within, es decir, que la principal fuente de variación en la tasa de informalidad a lo largo del período fue la movilidad de trabajadores desde empleos formales hacia empleos informales dentro de cada industria del sector. Como se mencionó anteriormente, ante un episodio de apertura comercial las firmas pueden reducir costos recurriendo a diversas estrategias una de las cuales es la implementación de mecanismos que incrementan la informalidad laboral. De acuerdo al resultado de esta descomposición, el despido de trabajadores y su posterior absorción como empleados informales en otra industria del sector no parece haber sido la reacción más frecuente. En cambio, la eliminación de los beneficios jubilatorios o el despido de trabajadores y su posterior incorporación como empleados informales en otras firmas de la misma industria fue la estrategia aplicada más extensamente ${ }^{22}$.

\footnotetext{
${ }^{22}$ Otra práctica que puede conducir al incremento en la informalidad laboral es el despido de trabajadores que luego sean incorporados como empleados informales en el sector de bienes no transables. Como se explicó anteriormente, esa posibilidad no es contemplada en el análisis.
} 
La estabilidad de la participación del empleo de cada industria en el empleo total del sector luego de los episodios de liberalización comercial es otra evidencia que respalda la estrategia de identificación. De acuerdo al mecanismo de ajuste de Heckscher-Ohlin, aquellos sectores que experimentan un aumento en su precio relativo luego de la apertura comercial (los que enfrentan una menor reducción de tarifas) deberían expandirse y lo contrario ocurriría con los que ven caer su precio relativo (los que reciben un recorte mayor de tarifas). Si esto así, se espera que el nivel de empleo de las industrias se ajuste de acuerdo a la magnitud del recorte de tarifas que hayan enfrentado. El Cuadro 8 muestra la variación promedio en la participación del empleo de cada industria luego de los episodios de apertura comercial. Con excepción de unas pocas industrias, todas experimentaron cambios inferiores al 10\% en su nivel de empleo luego de las reformas. Para aquellas que experimentaron los mayores cambios, no se encuentra una relación directa con la magnitud de la variación en las tarifas de acuerdo al mecanismo de ajuste de Heckscher-Ohlin. Es decir, que no habría evidencia a favor de la reasignación de empleo entre industrias. El mismo resultado se obtiene estimando un modelo para la participación del empleo controlando por las tarifas de cada industria y variables indicadoras de industria y tiempo: el coeficiente de la variable de tarifas es pequeño en magnitud y no significativo estadísticamente $^{23}$. Esta estabilidad en el nivel de empleo podría estar indicando la presencia de rigideces en el mercado laboral y costos de movilidad, aunque una explicación alternativa es que el empleo informal provee de un margen de ajuste adicional al interior de cada industria, ya sea eliminando los beneficios jubilatorios de los empleados actuales o recurriendo al despido y posterior absorción de esos empleados como trabajadores informales en otras firmas de la misma industria (Goldberg y Pavcnik, 2003). De acuerdo a la evidencia presentada, la segunda hipótesis resulta razonable, particularmente en el período en que la reforma laboral flexibilizó el funcionamiento de este mercado.

Si bien existe evidencia para sostener una estrategia de identificación basada en la variabilidad entre industrias de los cambios en la política comercial, resta argumentar respecto de la exogeneidad de este cambio diferencial en el patrón de protección. Teniendo en cuenta que las reformas comerciales son parte del proceso político, es inevitable la inquietud sobre la posible endogeneidad de los cambios de política comercial por motivos de política económica (Galiani y

\footnotetext{
${ }^{23}$ Modelo estimado por Mínimos Cuadrados Ordinarios. El coeficiente del logaritmo de tarifas es 0.014 con un error estándar robusto de 0.015 .
} 
Porto, 2008; Goldberg y Pavcnik, 2006). De hecho, la endogeneidad de la variable de tarifas por la omisión de otros factores de política sería inevitable en un análisis de corte transversal. La variación en el tiempo de los datos es, entonces, un factor importante respecto a este punto. La inclusión de variables indicadoras del período de tiempo permite controlar por shocks agregados vinculados a decisiones de política económica y a partir de ello las tarifas estarán determinadas por la tendencia internacional hacia la liberalización comercial $^{24}$ y por el nivel inicial de tarifas $^{25}$, dos factores exógenos al modelo (Galiani y Porto, 2008). Además de esto, el nivel de tarifas, al menos en la etapa del Mercosur, fue negociado dentro del marco de este acuerdo comercial, reduciendo el espacio para la acción de lobbies industriales. Alternativamente, podría implementarse el método de variables instrumentales. Sin embargo, la elección de un instrumento válido siempre es controversial por lo que la estrategia aquí presentada resulta superior.

Otra ventaja de la información disponible tiene que ver con la extensión del período de análisis que permite contar con más de un episodio de cambio en la política comercial. La comparación antes-después de un único episodio de liberalización comercial no estaría teniendo en cuenta que la comparación es entre una situación de protección y una de menor grado de protección y no entre un escenario de autarquía y uno de libre comercio (Goldberg y Pavcnik, 2006). Es por esto que un período extenso de tiempo refuerza la estrategia de identificación al ser posible comparar la evolución de las variables de interés durante esos cambios de política.

Aún cuando la estrategia de identificación propuesta presenta varias ventajas en términos del diseño y características de los datos, es necesario resaltar las posibles limitaciones. La principal restricción se encuentra en los argumentos que rechazan la posible endogeneidad de la variable de tarifas por motivos de política económica. La incorporación de variables indicadoras del período de tiempo permite controlar por aquellos shocks derivados de decisiones de política económica que tuvieron variación en el tiempo y afectaron de idéntica manera a todas las industrias. De la misma manera, la inclusión de variables indicadoras de industria permitirá controlar por aquellas características propias de cada industria que se mantuvieron constantes en el tiempo. Esto significa que aquellos factores de política que afectaron de manera diferencial a

\footnotetext{
${ }^{24}$ Por ejemplo, la liberalización de los noventa formó parte de un proceso más amplio hacia la integración comercial de todo el continente.

${ }^{25}$ Aquellas industrias con mayor nivel inicial de tarifas experimentarán el mayor cambio, mientras que las industrias con menor nivel inicial de protección enfrentarán menores recortes proporcionales de tarifas.
} 
cada industria, que presentaron variabilidad en el tiempo y que son relevantes para explicar la informalidad, permanecerán inobservados. De esta manera, si el cambio diferencial de tarifas entre industrias presenta algún grado de correlación con estas variables de política, ya no será posible asegurar la exogeneidad de la variable de interés. Otra posible limitación tiene que ver con la identificación de los efectos de la apertura comercial sobre la informalidad laboral al interior de cada industria. Si bien se mostró que el desplazamiento de trabajadores entre industrias no fue un factor detrás del cambio en la tasa de informalidad en el sector de manufacturas, queda sin explorar el movimiento de trabajadores desde este sector hacia el de bienes no transables.

\subsection{Reformas comerciales e informalidad laboral: estrategia empírica}

Siguiendo a Galiani y Porto (2008), el análisis formal del impacto de la apertura comercial sobre la informalidad laboral se basa en un modelo simple donde las tarifas de cada industria del sector manufacturero afectan la probabilidad de ser informal ${ }^{26}$. Para esto se utilizan los datos resultantes de la agregación de las Encuestas Permanentes de Hogares para el período $1980-2001^{27}$ y se estima un modelo lineal de la probabilidad de ser informal para el individuo $i$, empleado en la industria $j$ en el momento $t\left(Y_{i j t}\right)$, en el logaritmo de las tarifas que afectaron a esa industria en el momento $t\left(\ln \tau_{j t}\right)$, características individuales como género, edad, estado civil, variables indicadoras de jefe de hogar y nivel educativo, características del hogar como número de niños e ingreso adulto equivalente del hogar y características del empleo como tamaño de la

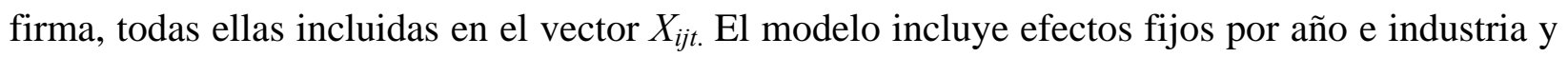
tendencias no lineales para cada industria.

$$
Y_{i j t}=X_{i j t} \beta_{x t}+\beta_{\tau} \ln \tau_{j t}+I_{j}+T_{t}+I_{j} * T_{t}+\varepsilon_{i j t}
$$

\footnotetext{
${ }^{26}$ La incorporación del sector de bienes no transables mediante una tarifa artificial constante (Alemán-Castilla, 2006) no parece adecuada conceptualmente. Si bien el impacto de esa tarifa ficticia sería absorbido por el efecto fijo, no es cierto que este sector enfrente una tarifa y tenga que ser incluido en el modelo. La disponibilidad de datos sobre tarifas efectivas justificaría la inclusión de este sector ya que en ese caso enfrentaría una tarifa por el uso de insumos transables en su proceso productivo.

${ }^{27}$ Con datos de corte transversal agregados el supuesto de observaciones idénticamente distribuidas ya no es válido dado que se espera que la distribución de las variables se modifique en el tiempo. Esto puede resolverse fácilmente incorporando variables indicadoras del período de tiempo.
} 
La inclusión de efectos fijos por industria y año permite controlar por características específicas de las industrias y por shocks agregados derivados del ciclo económico o decisiones de política. Por ejemplo, si el gobierno aumenta las tarifas durante una recesión y los trabajadores se desplazan de la formalidad hacia la informalidad como reacción ante los movimientos de la actividad económica, el coeficiente de la variable tarifas podría estar sesgado hacia arriba al captar el impacto del ciclo económico. Por otro lado, atributos inobservables de las industrias como su productividad, la capacidad para formar un lobby, la intensidad en el uso del capital pueden afectar la determinación de las tarifas y el empleo formal en cada una de ellas. Es decir, la inclusión de estos efectos fijos permite controlar por factores inobservables que podrían estar correlacionados con las tarifas y tener algún efecto independiente sobre la probabilidad de ser informal. Vinculado a este punto, debe mencionarse que no es posible controlar por la afiliación sindical de los trabajadores, aunque bajo el supuesto de que la sindicalización se mantuvo estable en el tiempo, este factor estaría captado con el efecto fijo a nivel de industria. Sin embargo, existe evidencia que indica que durante el período considerado, el modelo de determinación de la afiliación sindical habría sufrido modificaciones dando indicios de variaciones en la sindicalización a lo largo del tiempo (Marshall y Groisman, 2005). De esta manera, la ausencia de información sobre sindicalización individual se transforma en una limitación para el estudio.

La incorporación de tendencias industriales puede justificarse por la posible fuente de sesgo que la tendencia en la evolución temporal de la informalidad en cada industria puede representar en la estimación del impacto de las tarifas. Esto es, si la tendencia en la tasa de informalidad de cada industria a lo largo del tiempo presenta algún grado de correlación con los cambios observados en las tarifas, el efecto estimado de la apertura comercial sobre la informalidad laboral podría estar sesgado. Las particularidades observadas en la evolución de la tasa de informalidad en cada industria (Gráfico 4) determinaron la inclusión de tendencias no lineales para cada una de ellas mediante la interacción entre las variables indicadoras de industria y año. Adicionalmente, su incorporación permite controlar, al menos en parte, por la acción de ciertos factores específicos de cada industria que presentan variabilidad en el tiempo.

Como el regresor de interés varía a nivel de grupo (en este caso cada grupo vendría dado por la combinación de industrias y períodos de tiempo), la inferencia se realiza estimando errores estándar robustos agrupados a nivel de industria y año-industria. En caso contrario, se estaría 
sobreestimando la precisión al ignorar la correlación del término de error al interior de cada grupo.

La especificación de un modelo lineal cuando la variable dependiente es binaria puede justificarse recurriendo a los argumentos presentados por Angrist y Pishke (2008). Cuando la variable dependiente es limitada (binaria en este caso), la función de esperanza condicional será típicamente no lineal. La mayoría de los modelos con variable dependiente limitada se construyen alrededor de la transformación no lineal de un índice latente que sí lo es (por ejemplo, los modelos probit, logit o tobit). Estos modelos logran captar las características de la función de esperanza condicional asociada (en el caso de un modelo probit, las probabilidades estimadas estarán entre 0 y 1) pero la mayor complejidad para interpretar los resultados de un modelo de variable latente puede no ser necesaria. Angrist y Pishke (2008) muestran que los efectos marginales estimados a partir de un modelo lineal no difieren sustancialmente de los obtenidos mediante una especificación no lineal, y esto se cumple aún para valores de las variables explicativas alejados de los valores medios. En esta misma línea de argumentación, la complejidad de un modelo no lineal se justifica cuando existe interés en analizar los cambios en la probabilidad estimada para valores extremos de los regresores, ya que es allí donde los modelos no lineales presentan un ajuste diferencial respecto a un modelo lineal.

Una consideración importante a favor de un modelo lineal estimado por Mínimos Cuadrados Ordinarios (MCO) es la robustez conceptual que los modelos estructurales habitualmente no tienen (Angrist y Pishke, 2008). MCO es siempre la aproximación a la función de esperanza condicional que posee error cuadrático medio mínimo. De hecho, es posible pensar a MCO como un esquema para computar efectos marginales que tiene las ventajas de la simplicidad y comparabilidad entre estudios. Los modelos no lineales de variables latentes proveen de una ganancia de eficiencia pero requieren de un compromiso con la forma funcional y supuestos distributivos. Respecto a este punto, el cómputo de errores estándar robustos y agrupados para tener en cuenta la correlación del término de error al interior de cada grupo implica asumir que el modelo de elección binaria no está correctamente especificado. Esto ocurre porque al especificar de manera no lineal un modelo para $\operatorname{Pr}(\mathrm{Y}=1 / \mathrm{X})$, todos los momentos de la distribución de $\mathrm{Y} / \mathrm{X}$ también quedarán especificados. Por lo tanto, si se modifica la estructura de la matriz de varianzas y covarianzas y se le otorga la estructura "correcta" dadas las sospechas de 
correlación del término de error al interior de cada grupo, ello implicará que la especificación original de $\operatorname{Pr}(\mathrm{Y}=1 / \mathrm{X})$ no era adecuada (Wooldridge, 2002).

De acuerdo a la revisión de la literatura presentada en la Sección 2, la estrategia de estimación en dos etapas aplicada por Goldberg y Pavcnik (2003) se encuentra ampliamente difundida entre los estudios de este tipo. Como se mencionara en aquella sección, el origen de esa metodología tiene relación directa con la necesidad de ajustar la estimación de los errores estándar por la inclusión de variables con distinto nivel de agregación en el modelo. Sin embargo, las técnicas econométricas actuales permiten realizar esa adecuación sin necesidad de efectuar una estimación en dos etapas. Recurriendo al argumento presentado anteriormente, otro motivo para elegir la especificación de un modelo que incluya variables a nivel individual y grupal -es decir, a nivel de industria- es que existen características individuales que pueden presentar un alto grado de correlación a nivel de grupo. Si esto es así, estaríamos frente al mismo problema que la metodología intenta resolver, mientras que un único modelo con regresores a nivel individual y grupal podría corregir por la correlación al interior de cada industria. Un fundamento adicional para la estimación de un modelo agregado proviene del hecho de que la probabilidad de ser un trabajador informal depende de atributos individuales y de las características de la firma e industria a la que pertenece el trabajador. Un modelo de la probabilidad de empleo informal debería incluir, entonces, todas estas variables independientemente de su nivel de agregación.

\section{Resultados}

Los apartados siguientes muestran los principales resultados de la estimación del modelo presentado en la sección anterior y distintas variantes que se detallan a continuación. El Cuadro 9 en el Anexo Estadístico expone los restantes resultados de estos modelos.

\subsection{Modelo simple y con ajuste por acuerdo regional de comercio}

El Modelo 1 del Cuadro 1 se corresponde con la especificación simple donde se busca identificar el impacto de la apertura comercial mediante el logaritmo de las tarifas a las importaciones en cada industria del sector manufacturero. El resultado indica que la apertura 
comercial tuvo un impacto positivo y estadísticamente significativo sobre la probabilidad de ser un trabajador informal. Más específicamente, una reducción del 10\% en las tarifas a las importaciones genera un aumento en la probabilidad de ser informal de 0.25 puntos porcentuales. Esto se traduce en un incremento de 1.8 puntos porcentuales en una industria que experimentó una reducción del $72 \%$ en su tarifa a lo largo de todo el período, como fue el caso de la fabricación de maquinarias. Teniendo en cuenta que el aumento en la tasa de informalidad de esta industria fue de 17 puntos porcentuales (pasó de 2\% en el año 1980 a 19\% en el 2001), la apertura comercial estaría explicando, en este caso, el 11\% del cambio observado en la informalidad laboral.

Si bien Argentina firmó acuerdos comerciales con otros países durante el período considerado, la formación del Mercosur fue el evento comercial más importante. Los efectos inducidos por este acuerdo comercial se manifestaron nítidamente desde principios de los noventa, pero mientras que las negociaciones para su creación tuvieron lugar en marzo de 1991, ellas fueron finalmente legisladas en diciembre de 1994 (Porto, 2001). Para incluir el efecto de la formación del Mercosur se incorporó una variable indicadora que adopta el valor unitario a partir del año 1995 y hasta el año 2001, y la interacción entre esta variable y el logaritmo de las tarifas. Alternativamente, se estimó el modelo sólo para la etapa de vigencia de este acuerdo regional de comercio dentro del período que se analiza (1995-2001). Los resultados se muestran en las columnas correspondientes a los Modelos 2 y 3 del Cuadro 1 y son nuevamente coincidentes con los argumentos que se oponen a la apertura comercial. En ambas especificaciones el efecto estimado indica que existe una relación negativa y significativa estadísticamente entre las tarifas y la probabilidad de ser un trabajador informal en el sector manufacturero del Gran Buenos Aires y este efecto se acentúa a partir de la implementación del Mercosur.

El resultado obtenido al controlar por la variable indicadora de Mercosur y su interacción con el logaritmo de las tarifas (Modelo 2) muestra una profundización del efecto negativo de los aranceles sobre las chances de ser un trabajador informal a partir del año 1995: con anterioridad al acuerdo regional de comercio, una reducción del 10\% en las tarifas se asociaba a un aumento de 0.65 puntos porcentuales en la probabilidad de ser informal, mientras que ese incremento fue de 1 punto porcentual a partir de la entrada en vigencia del Mercosur.

El modelo estimado sólo para el sub-período de la muestra definido por los años 19952001 (Modelo 3) muestra un efecto muy superior en magnitud respecto al obtenido en el modelo 
estimado para el período completo. Una reducción del 10\% en las tarifas se asocia, en este caso, a un incremento de 2 puntos porcentuales en la probabilidad de ser un trabajador informal.

Los resultados hasta aquí encontrados sugieren la existencia de un impacto significativo estadísticamente de las políticas comerciales sobre la probabilidad de empleo informal. En particular, la liberalización comercial habría impactado positivamente sobre las chances de ser un trabajador informal en las industrias del sector manufacturero del Gran Buenos Aires, con una profundización del efecto a partir del año 1995, momento en que comenzó a tener vigencia el Mercado Común de acuerdo a lo establecido en el Tratado de Asunción del año 1991. La apertura comercial determinó que las firmas buscaran reducir costos y el incremento de la informalidad laboral parece haber sido una de las estrategias aplicadas. Teniendo en cuenta que la metodología implementada permite identificar efectos al interior de cada industria, los resultados muestran que las firmas recurrieron a la eliminación de los beneficios jubilatorios de sus empleados y/o al despido de trabajadores que luego fueron incorporados como empleados informales en otras firmas de la misma industria.

Cuadro 1: Impacto del logaritmo de tarifas sobre la probabilidad de empleo informal Industrias manufactureras del Gran Buenos Aires - Período 1980-2001

\begin{tabular}{|c|c|c|c|}
\hline & Modelo 1 & Modelo 2 & Modelo 3 \\
\hline Logaritmo de tarifas & -0.025 & -0.065 & -0.207 \\
\hline error estándar agrupado por industria & {$[0.010]^{\star \star}$} & {$[0.004]^{\star \star \star}$} & {$[0.008]^{\star * *}$} \\
\hline error estándar agrupado por año e industria & {$[0.012]^{\star \star}$} & {$[0.006]^{\star \star \star}$} & {$[0.010]^{\star \star \star}$} \\
\hline Interacción entre logaritmo de tarifas e indicadora de Mercosur & & -0.028 & \\
\hline error estándar agrupado por industria & & {$[0.003]^{\star \star \star}$} & \\
\hline error estándar agrupado por año e industria & & {$[0.004]^{\star \star \star}$} & \\
\hline Efectos fijos por industria & Si & Si & Si \\
\hline Efectos fijos por año & Si & No & Si \\
\hline Observaciones & 13508 & 13508 & 4145 \\
\hline $\mathrm{R}^{2}$ & 0.31 & 0.31 & 0.31 \\
\hline
\end{tabular}

Fuente: Elaboración propia.

Nota: Modelos estimados por MCO. Los restantes controles incluyen género, edad y su cuadrado, estado civil, nivel educativo, indicadora de jefe de hogar, número de niños en el hogar, ingreso adulto equivalente del hogar y tamaño de la firma.

*** significativo al 1\%; ** significativo al 5\%; * significativo al $10 \%$.

\subsection{Análisis de robustez}

Para testar la robustez de estas conclusiones, el Modelo 1 fue re-estimado para distintos sub-períodos de la muestra. Los resultados obtenidos se presentan en el Cuadro 2. 
De acuerdo a la evidencia preliminar presentada en la Sección 4, el episodio de apertura comercial más acentuado fue el de la década del noventa. Para testar que el resultado del Modelo 1 no esté determinado por ese episodio, el modelo fue re-estimado para los años comprendidos entre 1980 y 1989. El Modelo 4 muestra el impacto del logaritmo de las tarifas sobre la probabilidad de ser un trabajador informal para este sub-período. El resultado obtenido es robusto a las especificaciones anteriores e indica que una reducción en las tarifas a las importaciones se asocia a un aumento en la probabilidad de ser un empleado informal.

Otra preocupación vinculada a los resultados del Modelo 1 es el posible sesgo en el efecto estimado por la omisión de otros instrumentos de política comercial. Si bien existe evidencia de una correlación positiva y de escasa magnitud entre las tarifas y las barreras no arancelarias, es posible testar la validez de los resultados obtenidos para el período completo recurriendo al sub-período en que las barreras no arancelarias no fueron utilizadas. A principios de la década del noventa, este instrumento de política fue completamente eliminado como requisito previo a las negociaciones para la creación del Mercosur (Galiani y Porto, 2008). Más exactamente, entre los años 1988 y 1991 se produjo el desmantelamiento de este tipo de medidas. Puede afirmarse, entonces, que a partir del año 1992 las decisiones de política comercial fueron implementadas mediante variaciones en las tarifas a las importaciones. Dado esto, el Modelo 5 presenta el resultado de la estimación para el sub-período 1992-2001. El efecto de las tarifas sobre la probabilidad de empleo informal, en este caso, es nuevamente negativo y significativo en términos estadísticos.

Cuadro 2: Impacto del logaritmo de tarifas sobre la probabilidad de empleo informal - Análisis de robustez Industrias manufactureras del Gran Buenos Aires - Período 1980-2001

\begin{tabular}{lcc}
\hline & Modelo 4 & Modelo 5 \\
\hline $\begin{array}{l}\text { Logaritmo de tarifas } \\
\text { error estándar agrupado por industria }\end{array}$ & -0.058 & -0.093 \\
error estándar agrupado por año e industria & {$[0.008]^{\star \star \star}$} & {$[0.012]^{\star \star \star}$} \\
& {$[0.009]^{\star \star \star}$} & {$[0.008]^{\star \star \star}$} \\
Efectos fijos por industria & $\mathrm{Si}$ & $\mathrm{Si}$ \\
Efectos fijos por año & $\mathrm{Si}$ & $\mathrm{Si}$ \\
\hline Observaciones & 5175 & 6171 \\
\hline $\mathrm{R}^{2}$ & 0.30 & 0.31 \\
\hline Fuente: Elaboración propia. & \\
Nota: Modelos estimados por MCO. Los restantes controles incluyen género, edad y su \\
cuadrado, estado civil, nivel educativo, indicadora de jefe de hogar, número de niños en el \\
hogar, ingreso adulto equivalente del hogar y tamaño de la firma. \\
*** significativo al 1\%; ** significativo al 5\%; * significativo al 10\%.
\end{tabular}


Por último, para evaluar si los resultados encontrados al estimar un modelo lineal por MCO son compatibles con los hallazgos empíricos de Angrist y Pishke (2008) -es decir, los efectos marginales de un modelo lineal estimado por MCO no difieren sustancialmente de los obtenidos a partir de una especificación no lineal- los modelos fueron re-estimados proponiendo un modelo probit para la probabilidad de empleo informal. Los resultados se presentan en el Cuadro 10 del Anexo Estadístico e indican que el efecto marginal de las tarifas, evaluado en el valor medio de las variables explicativas, conserva la dirección respecto al efecto estimado por MCO en el caso de los Modelos 3-5 pero ocurre lo contario para los Modelos 1 y 2. Respecto a este punto puede argumentarse que los resultados de Angrist y Pishke (2008) son válidos cuando las estimaciones provienen de un modelo no lineal correctamente especificado. Como se mencionó anteriormente, el cálculo de errores estándar agrupados siempre será incompatible con la especificación del modelo no lineal para $\operatorname{Pr}(\mathrm{Y}=1 / \mathrm{X})$. Por otro lado, el método de máxima verosimilitud empleado para estimar un modelo probit es el más eficiente (entre la clase de estimadores que utilizan información sobre la distribución condicional de Y) al costo de obtener estimadores inconsistentes de los parámetros si alguna parte de la distribución no está correctamente especificada (Wooldridge, 2002). Con estos elementos, es posible esperar que la afirmación de Angrist y Pishke (2008) no se cumpla en este caso.

En conclusión, de acuerdo a los modelos estimados en primer lugar y a los resultados del análisis de robustez, puede concluirse que durante el período 1980-2001 la liberalización comercial tuvo un impacto positivo sobre la probabilidad de empleo informal en las industrias manufactureras del Gran Buenos Aires. Es decir, que la evidencia es consistente con los argumentos que se oponen a la apertura comercial: las firmas habrían buscado reducir costos siendo el incremento en la informalidad laboral una de las posibles estrategias aplicadas, ya sea eliminando beneficios jubilatorios como despidiendo trabajadores posteriormente incorporados como empleados informales en otras firmas de la misma industria. Adicionalmente, el efecto fue más acentuado a partir del año 1995, coincidiendo con la entrada en vigencia del Mercosur.

Una posible explicación de la profundización del impacto de la apertura comercial sobre la informalidad a partir del año 1995 es, precisamente, la entrada en vigencia del acuerdo regional de comercio. El Mercosur fue en sus orígenes un acuerdo comercial que a su característica de unión aduanera agregó la libre movilidad de factores productivos entre los países miembros y la adopción de una política comercial común. Es decir, que su creación 
implicó la ampliación del proceso de apertura comercial de inicios de la década del noventa y, por lo tanto, un mayor énfasis en el impacto sobre la probabilidad de empleo informal.

Una hipótesis alternativa para explicar el mayor impacto de la apertura comercial sobre la probabilidad de empleo informal a partir del año 1995, es el cambio tecnológico que tuvo lugar en la década del noventa: entre los años 1991 y 2000 la inversión extranjera directa creció a una tasa anual de 11.2\% mientras que la inversión bruta fija en equipamiento y maquinaria lo hizo al 6.8\% (Acosta y Gasparini, 2007). Por otro lado, estos mismos autores reportan que el precio relativo de los bienes de capital respecto a otros bienes finales se redujo un 10\% entre $1993 \mathrm{y}$ 2000, probablemente como resultado de la apreciación cambiaria y la reducción de tarifas ${ }^{28}$. El cambio tecnológico sesgado en favor del trabajo calificado suele ser el factor dominante para explicar los cambios en el mercado laboral y puede ser pensado como una respuesta endógena al proceso de liberalización comercial (Goldberg y Pavcnik, 2004). Si el cambio tecnológico es una variable relevante para explicar la probabilidad de empleo informal y si se espera que el cambio sesgado en favor del trabajo calificado incida positivamente sobre la informalidad laboral, el mayor impacto de las tarifas a partir del año 1995 podría explicarse por la incidencia del cambio tecnológico. Más allá de estas presunciones, cuyo desarrollo excede el propósito del trabajo, no existen argumentos formalizados que vinculen el cambio tecnológico a la informalidad en el mercado de trabajo.

\section{Comentarios finales}

Los resultados obtenidos indican que luego de controlar por características de los individuos, de las firmas en las que están empleados y por otros factores que pueden sesgar el resultado como la tendencia en la evolución temporal de la informalidad en cada industria, la apertura comercial, ceteris paribus, tuvo un impacto positivo sobre la probabilidad de empleo informal en las industrias del sector manufacturero del Gran Buenos Aires durante el período 1980-2001. El efecto identificado respalda las teorías que indican que ante la apertura comercial las firmas buscarán reducir costos y una de las posibles estrategias es recurrir a modalidades que resultan en incrementos de la informalidad laboral. De acuerdo a las características de la

\footnotetext{
${ }^{28}$ Entre 1980 y 2001, la tarifa de la industria de fabricación de maquinarias se redujo en un 75\%.
} 
estrategia de identificación implementada, existe evidencia de que al interior de cada industria las firmas eliminaron los beneficios jubilatorios de sus empleados y/o despidieron trabajadores que luego fueron absorbidos como empleados informales en otras firmas de la misma industria. De acuerdo al efecto estimado en el Modelo 1, la apertura comercial explica, en promedio, un 4\% del aumento observado en la tasa de informalidad de estas industrias durante el período considerado $^{29}$. O, equivalentemente, de los 18 puntos porcentuales de aumento en la tasa de informalidad de este sector (pasó de 16\% en 1980 a 34\% en el año 2001), alrededor de un punto se explica por la política comercial.

Teniendo en cuenta la discusión inicial sobre la dificultad de cuantificar el impacto de la informalidad laboral sobre el bienestar de los trabajadores, no es posible valorar normativamente estos resultados. Sin embargo, la población de interés en este caso está conformada por aquellos trabajadores asalariados y existe evidencia que vincula el fenómeno de informalidad laboral de esta categoría ocupacional a la perspectiva de “exclusión”. Los asalariados informales tienden a buscar empleos más deseables, ya sea como asalariados formales o como trabajadores independientes (Perry et al., 2007). Para el caso particular del Gran Buenos Aires, los trabajadores informales, independientemente de su categoría ocupacional, tienden a estar insatisfechos con sus empleos y desearían ingresar a la formalidad pero enfrentan restricciones para hacerlo (Waisgrais y Sarabia, 2008). La informalidad estaría reflejando, entonces, la decisión de las empresas para las cuales trabajan y no una elección propia. Dado esto, es posible esperar que la apertura comercial haya representado un cambio negativo para los trabajadores asalariados durante el período analizado.

Por último, es importante mencionar que las características de los datos utilizados fueron determinantes de la estrategia de análisis empleada. Más específicamente, los datos de corte transversal agrupados no permiten observar los movimientos de los trabajadores entre la formalidad y la informalidad a lo largo del tiempo. El análisis en base a datos de panel permitiría ver la evolución de los individuos en el mercado de trabajo representando un claro avance en esta línea de análisis.

\footnotetext{
${ }^{29}$ Para obtener este resultado se calculó el cambio en la probabilidad de empleo informal de cada industria según la variación de tarifas experimentada por cada una de ellas entre 1980 y 2001. Luego se computó la proporción que ese aumento estimado representa en la variación observada en la tasa de informalidad de cada industria.
} 


\section{Bibliografía}

Acosta, P. y Gasparini, L. (2007): “Capital Accumulation, Trade Liberalization and Rising Wage Inequality: The Case of Argentina”, Economic Development and Cultural Change 55 (4).

Alemán-Castilla, B. (2006): “The Effect of Trade Liberalization on Informality and Wages: Evidence from Mexico”. CEP Discussion Paper 763.

Angrist, J. y Pishke, J. (2008): Mostly Harmless Econometrics: An Empiricist's Companion. Princeton University Press. Capítulo 3.

Attanasio, O., Goldberg, P. y Pavcnik, N. (2003): “Trade Reforms and Wage Inequality in Colombia”. National Bureau of Economic Research. Working Paper 9830.

Bosch, M., Goni, E. y Maloney, W. (2007): “The Determinants of Rising Informality in Brazil: Evidence from Gross Worker Flows”. IZA Discussion Paper 2970.

Bottini, N. y Gasiorek, M. (2009): “Trade and Job Reallocation: Evidence for Morocco”. Liuc Papers 224, Serie Economia e Impresa, 60, gennaio 2009.

CEDLAS (2010). Socio-Economic Database for Latin America and the Caribbean (SEDLAC). Proyecto conjunto entre el Centro de Estudios Distributivos, Laborales y Sociales (UNLP) y el Banco Mundial. Disponible online en www.depeco.econo.unlp.edu.ar/sedlac.

Dickens, W. y Katz, L. (1987): "Inter-Industry Wage Differences and Industry Characteristics”. En K. Lang y J.S. Leonard (eds.), Unemployment and the Structure of Labor Markets, Basil Blackwell.

Fiess, N. y Fugazza, M. (2008): “Trade liberalisation and Informality: New Stylized Facts”. Policy Issues in International Trade and Commodities. Study Series 43.

Galiani, S. y Porto, G. (2008): “Trends in Tariff Reforms and Trends in the Structure of Wages”. Forthcoming in the Review of Economics and Statistics.

Galiani, S. y Sanguinetti, P. (2003): "The impact of trade liberalization on wage inequality: evidence from Argentina”, Journal of Development Economics 72 (2003) 497- 513.

Galiani, S. y Weinschelbaum, F. (2006): “Modeling Informality Formally: Households and Firms”, Documento de Trabajo No 47. Centro de Estudios Distributivos, Laborales y Sociales (CEDLAS). 
Gasparini, L. y Cruces, G. (2008): "Una Distribución en Movimiento: El Caso de Argentina”, Revista Desarrollo Económico 192 (48), 2009.

Gasparini, L. y Tornarolli, L. (2007): "Labor Informality in Latin America and the Caribbean: Patterns and Trends from Household Survey Microdata”, Documento de Trabajo No 46. Centro de Estudios Distributivos, Laborales y Sociales (CEDLAS).

Goldberg, P. y Pavcnik, N. (2003): "The Response of the Informal Sector to Trade Liberalization”. Journal of Development Economics 72 (2003) 463- 496.

Goldberg, P. y Pavcnik, N. (2003): "Trade, Wages and the Political Economy of Trade Protection: Evidence from the Colombian Trade Reforms”. Journal of International Economics, 66, 75-105.

Goldberg, P. y Pavcnik, N. (2004): “Trade, Inequality, and Poverty: What Do We Know? Evidence from Recent Trade Liberalization Episodes in Developing Countries”. Brookings Trade Forum 2004, 223-269.

Goldberg, P. y Pavcnik, N. (2006): “Distributional Effects of Globalization in Developing Countries”. Journal of Economic Literature March 2007, 45(1), pp. 39-82.

Katz, L y Summers, L. (1989): “Industry Rents: Evidence and Implications”, Brookings Papers on Economic Activity: Microeconomics, 209-275, Washington D.C.

Kaufmann, D. y Kaliberda, A. (1996): "Integrating the unofficial economy into the dynamics of post socialist-economies”. En Economic Transition in the newly independent states, editado por B. Kaminsky. Armonk, NY: M.E. Sharpe.

Maloney, W. (2003): “Informality Revisited”. World Bank Policy Research Working Paper 2965.

Marcouiller, D., Ruiz de Castilla, V. y Woodruff, Ch. (2007): "Formal Measures of the Informal Sector Wage Gap in Mexico, El Salvador, and Peru”, The University of Chicago Press.

Marshall, A. y Groisman, F. (2005): “Sindicalización en la Argentina: Análisis desde la Perspectiva de los Determinantes de la Afiliación Individual”, Estudio preparado para el 7mo. Congreso Nacional de Estudios del Trabajo, ASET.

OIT (1991): "El dilema del sector no estructurado”, Memoria del Director General, CIT, 1991, Ginebra. 
Perry, G., Maloney, W., Arias, O., Fajnzylber, P., Mason, A. y Saavedra-Chanduvi, J. (2007): “Informalidad: Escape y Exclusión”, Estudios del Banco Mundial sobre América Latina y el Caribe.

Porto, G. (2001): “Efectos Distributivos de la Política Comercial Argentina: Aspectos Regionales y Nacionales”, Serie de Estudios en Finanzas Públicas, Nro. 10.

Schneider, F. (2007): "Shadow Economies and Corruption all over the World: New Estimates for 145 Countries”, Economics: The Open-Access, Open-Assessment E-journal, Vol. $1,2007$.

Torre, J. C. y Gerchunoff, P. (1999): “La Economía política de las Reformas Institucionales en Argentina. Los Casos de la Política de Privatización de Entel, la Reforma de la Seguridad Social y la Reforma Laboral”, Banco Interamericano de Desarrollo, Red de Centros de Investigación, Working Paper R-349.

Ulyssea, G. (2006): "Regulation of Entry, Labor Market Institutions and the Informal Sector”. Journal of Development Economics, Vol 91, Issue 1, pp 87-99.

Waisgrais, S. y Sarabia, M. (2008): “La heterogeneidad de la informalidad”, En Aportes a una nueva visión de la informalidad laboral en la Argentina, Banco Mundial y Ministerio de Trabajo, Empleo y Seguridad Social.

Wooldridge, J. (2002): Econometric Analysis of Cross Section and Panel Data, MIT Press, Cambridge. 


\section{Anexo Estadístico}

\section{Cuadro 3: Industrias del sector manufacturero}

\begin{tabular}{|c|c|}
\hline Industria 1 & Elaboración de productos alimenticios \\
\hline Industria 2 & Elaboración de bebidas \\
\hline Industria 3 & Elaboración de productos de tabaco \\
\hline Industria 4 & Fabricación de productos textiles \\
\hline Industria 5 & Fabricación de prendas de vestir, excepto calzado \\
\hline Industria 6 & $\begin{array}{l}\text { Curtido y adobo de cueros; fabricación de maletas, bolsos de mano y artículos de talabartería y } \\
\text { guarnicionería }\end{array}$ \\
\hline Industria 7 & Fabricación de calzado \\
\hline Industria 8 & $\begin{array}{l}\text { Producción de madera y fabricación de productos de madera y corcho, excepto muebles; fabricación } \\
\text { de artículos de paja y de materiales trenzables }\end{array}$ \\
\hline Industria 9 & Fabricación de muebles \\
\hline Industria 10 & Fabricación de papel y de productos de papel \\
\hline Industria 11 & Editoriales e imprentas \\
\hline Industria 12 & Fabricación de sustancias y productos químicos \\
\hline Industria 13 & Fabricación de productos de la refinación del petróleo y combustible nuclear \\
\hline Industria 14 & Fabricación de productos de caucho \\
\hline Industria 15 & Fabricación de productos de plástico \\
\hline Industria 16 & Fabricación de vidrio y productos de vidrio \\
\hline Industria 17 & Fabricación de otros productos minerales no metálicos \\
\hline Industria 18 & Fabricación de metales comunes \\
\hline Industria 19 & Fabricación de productos elaborados de metal, excepto maquinaria y equipo \\
\hline Industria 20 & Fabricación de maquinaria, excepto eléctrica \\
\hline Industria 21 & Fabricación de maquinaria y aparatos eléctricos n.c.p. \\
\hline Industria 22 & Fabricación de vehículos automotores, remolques y semirremolques \\
\hline Industria 23 & Fabricación de instrumentos médicos, ópticos y de precisión \\
\hline Industria 24 & Industrias manufactureras n.c.p. \\
\hline
\end{tabular}

Fuente: Elaboración propia en base a EPH. 
Cuadro 4: Estadísticas descriptivas

Tarifa mediana, industrias según ISIC a 3 dígitos

\begin{tabular}{lcccc}
\hline Año & Obs & Media & Mediana & $\begin{array}{c}\text { Desvío } \\
\text { estándar }\end{array}$ \\
\hline 1980 & 1243 & 40.95 & 39.50 & 10.17 \\
1985 & 1261 & 31.55 & 33.75 & 6.37 \\
1986 & 1360 & 29.98 & 28.50 & 6.98 \\
1987 & 1336 & 29.39 & 28.00 & 7.55 \\
1988 & 1491 & 29.42 & 28.00 & 7.54 \\
1989 & 1531 & 31.65 & 32.00 & 8.03 \\
1990 & 932 & 20.56 & 20.31 & 4.64 \\
1991 & 971 & 15.33 & 14.00 & 5.51 \\
1992 & 968 & 17.43 & 17.75 & 4.95 \\
1993 & 954 & 21.34 & 22.08 & 6.27 \\
1994 & 870 & 20.29 & 21.25 & 5.73 \\
1995 & 843 & 18.52 & 17.80 & 3.91 \\
1996 & 769 & 19.21 & 18.37 & 3.73 \\
1997 & 812 & 19.23 & 18.24 & 3.98 \\
1998 & 809 & 18.8 & 17.58 & 4.00 \\
1999 & 752 & 18.6 & 17.43 & 3.96 \\
2000 & 731 & 18.73 & 18.72 & 3.46 \\
2001 & 654 & 25.51 & 24.86 & 5.28 \\
\hline
\end{tabular}

Fuente: Elaboración propia en base a EPH y Galiani y Porto (2008).

Cuadro 5: Encuesta Permanente de Hogares

Encuestas utilizadas y tamaño de la muestra

Individuos de entre 15 y 65 años de edad empleados en el sector manufacturero

\begin{tabular}{llc}
\hline Año & Onda & Observaciones \\
\hline 1980 & Octubre & 1243 \\
1985 & Octubre & 1261 \\
1986 & Octubre & 1360 \\
1987 & Octubre & 1336 \\
1988 & Octubre & 1491 \\
1989 & Octubre & 1531 \\
1990 & Octubre & 932 \\
1991 & Octubre & 971 \\
1992 & Octubre & 968 \\
1993 & Octubre & 954 \\
1994 & Octubre & 870 \\
1995 & Octubre & 843 \\
1996 & Octubre & 769 \\
1997 & Octubre & 812 \\
1998 & Octubre & 809 \\
1999 & Octubre & 752 \\
2000 & Octubre & 731 \\
2001 & Octubre & 654 \\
\hline
\end{tabular}

Fuente: Elaboración propia en base a EPH. 
Cuadro 6: Caracterización de trabajadores informales en el sector manufacturero Individuos asalariados de entre 15 y 65 años de edad

\begin{tabular}{|c|c|c|c|c|c|c|c|}
\hline & & 1980 & 1988 & 1992 & 1996 & 2000 & 2001 \\
\hline \multirow{3}{*}{ Salario horario } & Informal & - & 1.947 & 2.780 & 2.906 & 2.728 & 3.225 \\
\hline & & & (0.118) & (0.185) & $(0.163)$ & $(0.218)$ & $(0.324)$ \\
\hline & Formal & - & $\begin{array}{c}3.560 \\
(0.130)\end{array}$ & $\begin{array}{c}3.657 \\
(0.123)\end{array}$ & $\begin{array}{c}4.179 \\
(0.221)\end{array}$ & $\begin{array}{c}4.616 \\
(0.242)\end{array}$ & $\begin{array}{c}4.546 \\
(0.225)\end{array}$ \\
\hline \multirow{4}{*}{$\begin{array}{c}\text { Horas } \\
\text { semanales de } \\
\text { trabajo }\end{array}$} & Informal & 44.250 & 44.492 & 45.823 & 42.208 & 42.888 & 39.385 \\
\hline & & (1.308) & $(0.900)$ & $(1.087)$ & (1.322) & (1.415) & $(1.500)$ \\
\hline & Formal & 47.764 & 47.426 & 47.089 & 46.991 & 48.267 & 47.408 \\
\hline & & $(0.460)$ & $(0.378)$ & $(0.469)$ & $(0.473)$ & $(0.533)$ & $(0.646)$ \\
\hline \multirow{4}{*}{ Hombres (\%) } & Informal & 61.061 & 57.729 & 66.446 & 61.444 & 61.854 & 62.438 \\
\hline & & (3.879) & (2.797) & (3.298) & (3.383) & (3.461) & (3.682) \\
\hline & Formal & 76.896 & 78.383 & 77.015 & 79.752 & 78.087 & 76.328 \\
\hline & & $(1.420)$ & $(1.371)$ & (1.738) & $(1.945)$ & (2.079) & (2.299) \\
\hline \multirow{4}{*}{ Edad } & Informal & 30.202 & 30.601 & 29.991 & 31.699 & 32.364 & 32.571 \\
\hline & & $(1.075)$ & $(0.748)$ & $(0.860)$ & $(0.872)$ & $(0.849)$ & $(0.872)$ \\
\hline & Formal & 35.477 & 37.067 & 37.033 & 37.444 & 37.073 & 37.113 \\
\hline & & $(0.408)$ & $(0.410)$ & $(0.516)$ & $(0.571)$ & $(0.566)$ & $(0.627)$ \\
\hline \multirow{4}{*}{$\begin{array}{c}\text { No calificados } \\
(\%)\end{array}$} & Informal & 80.870 & 82.205 & 80.538 & 75.834 & 71.909 & 68.535 \\
\hline & & (3.129) & $(2.165)$ & $(2.765)$ & $(2.975)$ & $(3.202)$ & (3.531) \\
\hline & Formal & 75.630 & 70.629 & 66.982 & 63.667 & 54.456 & 48.824 \\
\hline & & $(1.446)$ & $(1.517)$ & $(1.943)$ & $(2.328)$ & $(2.503)$ & $(2.703)$ \\
\hline \multirow{4}{*}{$\begin{array}{c}\text { Semicalificados } \\
(\%)\end{array}$} & Informal & 18.598 & 14.406 & 16.491 & 21.223 & 25.023 & 26.850 \\
\hline & & (3.095) & (1.988) & $(2.592)$ & $(2.842)$ & $(3.086)$ & (3.369) \\
\hline & Formal & 20.003 & 23.042 & 25.510 & 29.947 & 31.880 & 40.353 \\
\hline & & $(1.348)$ & $(1.402)$ & $(1.801)$ & $(2.217)$ & $(2.342)$ & $(2.653)$ \\
\hline \multirow{4}{*}{ Calificados (\%) } & Informal & 0.000 & 2.759 & 2.971 & 2.943 & 3.067 & 4.615 \\
\hline & & $(0.000)$ & $(0.927)$ & (1.186) & (1.175) & (1.228) & $(1.595)$ \\
\hline & Formal & 3.492 & 4.910 & 6.823 & 6.148 & 13.663 & 10.824 \\
\hline & & $(0.618)$ & $(0.719)$ & (1.042) & (1.162) & $(1.726)$ & (1.680) \\
\hline \multirow{4}{*}{ Casados (\%) } & Informal & 43.445 & 43.580 & 46.886 & 50.332 & 50.210 & 52.309 \\
\hline & & (3.943) & $(2.807)$ & $(3.485)$ & $(3.475)$ & $(3.562)$ & (3.797) \\
\hline & Formal & 62.217 & 67.767 & 68.774 & 66.866 & 69.902 & 67.481 \\
\hline & & $(1.633)$ & $(1.556)$ & (1.914) & $(2.278)$ & $(2.305)$ & $(2.533)$ \\
\hline \multirow{4}{*}{$\begin{array}{c}\text { Jefe de hogar } \\
\text { (\%) }\end{array}$} & Informal & 31.567 & 30.610 & 38.739 & 35.758 & 37.368 & 41.029 \\
\hline & & (3.698) & (2.609) & $(3.402)$ & (3.331) & $(3.447)$ & $(3.740)$ \\
\hline & Formal & 58.245 & 63.113 & 59.287 & 61.685 & 61.654 & 58.789 \\
\hline & & $(1.661)$ & $(1.607)$ & $(2.030)$ & (2.353) & $(2.443)$ & (2.662) \\
\hline \multirow{4}{*}{ Conyuge (\%) } & Informal & 15.26 & 16.05 & 13.54 & 16.25 & 16.99 & 16.53 \\
\hline & & $(0.029)$ & $(0.021)$ & $(0.024)$ & $(0.023)$ & $(0.027)$ & $(0.028)$ \\
\hline & Formal & 6.23 & 8.24 & 10.45 & 8.87 & 11.56 & 13.13 \\
\hline & & $(0.008)$ & $(0.009)$ & $(0.013)$ & $(0.014)$ & $(0.016)$ & $(0.018)$ \\
\hline \multirow{4}{*}{$\begin{array}{l}\text { Número de niños } \\
\text { en el hogar }\end{array}$} & Informal & 1.124 & 1.325 & 1.356 & 1.400 & 1.465 & 1.544 \\
\hline & & $(0.100)$ & (0.090) & (0.110) & $(0.110)$ & $(0.121)$ & $(0.130)$ \\
\hline & Formal & 1.155 & 1.110 & 1.204 & 1.038 & 0.966 & 0.917 \\
\hline & & $(0.045)$ & $(0.043)$ & $(0.059)$ & $(0.060)$ & $(0.060)$ & $(0.062)$ \\
\hline \multirow{4}{*}{$\begin{array}{l}\text { Ingreso adulto } \\
\text { equivalente del } \\
\text { hogar }\end{array}$} & Informal & 314.280 & 286.802 & 363.478 & 302.282 & 311.161 & 305.162 \\
\hline & & (15.936) & (12.125) & (19.415) & (15.826) & (24.256) & (27.349) \\
\hline & Formal & 381.299 & 410.216 & 425.345 & 443.428 & 531.622 & 481.615 \\
\hline & & (9.647) & (17.376) & $(14.519)$ & (27.189) & $(36.278)$ & $(27.469)$ \\
\hline \multirow{4}{*}{$\begin{array}{l}\text { Empleados en } \\
\text { firmas grandes } \\
\text { (\%) }\end{array}$} & Informal & 55.255 & 52.436 & 53.815 & 51.103 & 55.526 & 55.401 \\
\hline & & (4.312) & (3.056) & (3.812) & (3.608) & (3.714) & (3.881) \\
\hline & Formal & 91.624 & 94.002 & 91.418 & 86.377 & 92.126 & 90.357 \\
\hline & & $(0.954)$ & $(0.819)$ & (1.277) & $(1.692)$ & $(1.385)$ & $(1.620)$ \\
\hline
\end{tabular}

Fuente: Elaboración propia en base a EPH.

Notas: Salario horario en pesos a precios del año 1999.

Son individuos calificados aquellos que poseen nivel educativo superior completo, semicalificados los que poseen superior incompleto o secundario completo y no calificados aquellos con secundario incompleto o inferior.

El número de niños en el hogar considera a aquellos individuos de 15 años de edad o menos.

Las firmas grandes son aquellas con 5 o más empleados. 
Cuadro 7: Descomposición del cambio en la tasa de informalidad del sector manufacturero Años 1980-2001

\begin{tabular}{ccc}
\hline $\begin{array}{c}\text { Cambio en la } \\
\text { informalidad }\end{array}$ & Efecto Within & Efecto Between \\
\hline 17.93 & 17.88 & 0.05 \\
& $(99.72 \%)$ & $(0.28 \%)$ \\
\hline
\end{tabular}

Fuente: Elaboración propia en base a EPH.

Cuadro 8: Variación promedio de la participación del empleo de cada industria en el empleo total

\begin{tabular}{lcc}
\hline & $\begin{array}{c}\text { Primer } \\
\text { episodio }\end{array}$ & $\begin{array}{c}\text { Segundo } \\
\text { episodio }\end{array}$ \\
\hline Industria 1 & 2.00 & 0.05 \\
Industria 2 & -2.99 & 8.57 \\
Industria 3 & 24.61 & 22.15 \\
Industria 4 & -5.48 & -9.59 \\
Industria 5 & -2.75 & 5.36 \\
Industria 6 & 5.09 & -3.30 \\
Industria 7 & -8.40 & -0.81 \\
Industria 8 & 33.49 & 2.94 \\
Industria 9 & -4.46 & 5.01 \\
Industria 10 & 8.19 & -6.27 \\
Industria 11 & 5.10 & 6.11 \\
Industria 12 & -3.88 & 5.89 \\
Industria 13 & 21.58 & 55.66 \\
Industria 14 & -7.79 & -1.42 \\
Industria 15 & 15.70 & 9.59 \\
Industria 16 & -15.24 & 1.70 \\
Industria 17 & 6.06 & 32.59 \\
Industria 18 & -0.91 & 14.38 \\
Industria 19 & -0.92 & 3.27 \\
Industria 20 & 16.72 & 5.84 \\
Industria 21 & 9.23 & -0.63 \\
Industria 22 & 2.44 & 1.82 \\
Industria 23 & 52.23 & 15.58 \\
Industria 24 & 49.90 & 13.32 \\
\hline
\end{tabular}

Fuente: Elaboración propia en base a EPH.

Nota: El primer episodio de liberalización comprende los años 1985-1988 y el segundo, los años 1990-2000. 
Cuadro 9: Modelo lineal de probabilidad de empleo informal

\begin{tabular}{|c|c|c|c|c|c|}
\hline & Modelo 1 & Modelo 2 & Modelo 3 & Modelo 4 & Modelo 5 \\
\hline \multirow[t]{3}{*}{ Logaritmo de tarifas } & -0.025 & -0.065 & -0.207 & -0.058 & -0.093 \\
\hline & {$[0.010]^{\star \star}$} & {$[0.004]^{\star \star \star}$} & {$[0.008]^{\star \star \star}$} & {$[0.008]^{\star \star \star}$} & {$[0.012]^{\star \star \star}$} \\
\hline & {$[0.012]^{\star \star}$} & {$[0.006]^{\star \star \star}$} & {$[0.010]^{\star \star \star}$} & {$[0.009]^{\star \star \star}$} & {$[0.008]^{\star \star \star}$} \\
\hline \multirow[t]{3}{*}{ Interacción entre logaritmo de tarifas e indicadora de Mercosur } & & -0.028 & & & \\
\hline & & {$[0.003]^{\star \star *}$} & & & \\
\hline & & {$[0.004]^{\star \star *}$} & & & \\
\hline \multirow[t]{3}{*}{$=1$ si año $>=1995$} & & 0.000 & & & \\
\hline & & {$[0.000]$} & & & \\
\hline & & {$[0.000]$} & & & \\
\hline \multirow[t]{3}{*}{$=1$ si hombre } & -0.06 & -0.06 & -0.101 & -0.026 & -0.085 \\
\hline & {$[0.017]^{\star * *}$} & {$[0.017]^{\star * *}$} & {$[0.035]^{\star * *}$} & [0.019] & {$[0.030]^{\star * *}$} \\
\hline & {$[0.011]^{\star * *}$} & {$[0.011]^{\star \star *}$} & {$[0.021]^{\star \star *}$} & [0.016] & {$[0.017]^{\star \star *}$} \\
\hline \multirow[t]{3}{*}{ edad } & -0.036 & -0.036 & -0.039 & -0.032 & -0.039 \\
\hline & {$[0.004]^{\star \star *}$} & {$[0.004]^{\star \star *}$} & {$[0.005]^{\star \star *}$} & {$[0.002]^{\star * *}$} & {$[0.005]^{\star \star *}$} \\
\hline & {$[0.002]^{\star * *}$} & {$[0.002]^{\star * *}$} & {$[0.004]^{\star \star \star}$} & {$[0.003]^{\star * *}$} & {$[0.003]^{\star \star \star}$} \\
\hline \multirow[t]{3}{*}{ edad $^{2}$} & 0.000 & 0.000 & 0.000 & 0.000 & 0 \\
\hline & {$[0.000]^{\star \star *}$} & {$[0.000]^{\star \star *}$} & {$[0.000]^{\star \star *}$} & {$[0.000]^{\star \star *}$} & {$[0.000]^{\star \star *}$} \\
\hline & {$[0.000]^{\star \star *}$} & {$[0.000]^{\star \star *}$} & {$[0.000]^{\star \star *}$} & {$[0.000]^{\star \star \star}$} & {$[0.000]^{\star \star *}$} \\
\hline \multirow[t]{3}{*}{$=1$ si casado } & -0.027 & -0.027 & -0.030 & -0.030 & -0.026 \\
\hline & {$[0.014]^{*}$} & {$[0.014]^{*}$} & {$[0.022]$} & {$[0.014]^{\star \star}$} & {$[0.019]$} \\
\hline & {$[0.011]^{\star *}$} & {$[0.011]^{\star \star}$} & {$[0.020]$} & {$[0.012]^{\star \star}$} & [0.017] \\
\hline \multirow[t]{3}{*}{$=1$ si jefe del hogar } & -0.023 & -0.023 & -0.023 & -0.040 & -0.009 \\
\hline & [0.014] & [0.014] & [0.018] & {$[0.014]^{\star \star \star}$} & [0.019] \\
\hline & {$[0.011]^{\star *}$} & {$[0.011]^{* *}$} & {$[0.020]$} & {$[0.013]^{\star \star *}$} & {$[0.016]$} \\
\hline \multirow{3}{*}{$=1$ si semicalificado } & -0.045 & -0.045 & -0.0420 & -0.0200 & -0.052 \\
\hline & {$[0.010]^{\star \star *}$} & {$[0.010]^{\star \star *}$} & {$[0.019]^{\star \star}$} & {$[0.011]^{*}$} & {$[0.012]^{\star \star \star}$} \\
\hline & {$[0.009]^{\star \star \star}$} & {$[0.009]^{\star \star \star}$} & {$[0.015]^{\star \star \star}$} & {$[0.012]^{\star}$} & {$[0.013]^{\star \star \star}$} \\
\hline \multirow[t]{3}{*}{$=1$ si calificado } & -0.026 & -0.026 & -0.037 & 0.007 & -0.039 \\
\hline & [0.023] & {$[0.023]$} & {$[0.044]$} & {$[0.015]$} & [0.034] \\
\hline & {$[0.015]^{*}$} & {$[0.015]^{\star}$} & {$[0.028]$} & {$[0.019]$} & {$[0.022]^{\star}$} \\
\hline
\end{tabular}

Fuente: Elaboración propia.

Nota: Modelos estimados por MCO.

Son individuos semicalificados aquellos con nivel educativo secundario completo o superior incompleto y calificados los que poseen superior completo como máximo nivel educativo alcanzado.

Errores estándar agrupados entre corchetes. En primer lugar se indica la agrupación por industria; en segundo, por año e industria.

*** significativo al 1\%; ** significativo al 5\%; * significativo al 10\%.

Cuadro 10: Efectos marginales de un modelo probit de la probabilidad de empleo informal

\begin{tabular}{|c|c|c|c|c|c|}
\hline & Modelo 1 & Modelo 2 & Modelo 3 & Modelo 4 & Modelo 5 \\
\hline Logaritmo de tarifas & 0.097 & 0.014 & -0.098 & -0.032 & -0.230 \\
\hline error estándar agrupado por industria & {$[0.008]^{\star \star \star}$} & [0.009] & {$[0.015]^{\star \star \star}$} & {$[0.005]^{\star \star \star}$} & {$[0.016]^{\star * *}$} \\
\hline error estándar agrupado por año e industria & {$[0.004]^{\star \star \star}$} & {$[0.008]^{*}$} & {$[0.016]^{\star \star \star}$} & {$[0.007]^{\star \star \star}$} & {$[0.009]^{\star \star *}$} \\
\hline Interacción entre logaritmo de tarifas e indicadora de Mercosur & & 0.028 & & & \\
\hline error estándar agrupado por industria & & {$[0.004]^{\star * *}$} & & & \\
\hline error estándar agrupado por año e industria & & {$[0.003]^{\star \star *}$} & & & \\
\hline Efectos fijos por industria & Si & $\mathrm{Si}$ & Si & $\mathrm{Si}$ & $\mathrm{Si}$ \\
\hline Efectos fijos por año & $\mathrm{Si}$ & No & $\mathrm{Si}$ & $\mathrm{Si}$ & $\mathrm{Si}$ \\
\hline Observaciones & 13508 & 13508 & 4145 & 5175 & 6171 \\
\hline Pseudo $\mathrm{R}^{2}$ & 0.28 & 0.28 & 0.26 & 0.29 & 0.27 \\
\hline
\end{tabular}

Fuente: Elaboración propia.

Nota: Efectos marginales evaluados en el valor promedio de las variables explicativas.

*** significativo al 1\%; ** significativo al 5\%; * significativo al $10 \%$. 


\section{Gráfico 4: Tarifas a las importaciones e informalidad en cada industria del sector manufacturero}

Industrias a 3 dígitos ISIC

Fuente: Elaboración propia en base a EPH-Puntual y Galiani y Porto (2008).

1

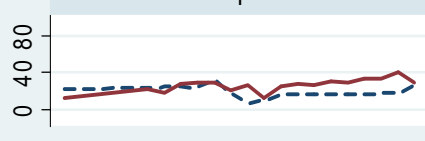

5

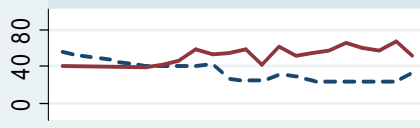

9

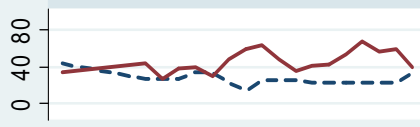

13

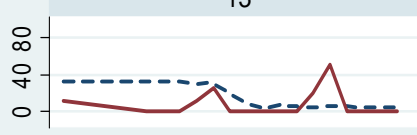

17

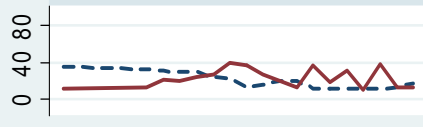

21

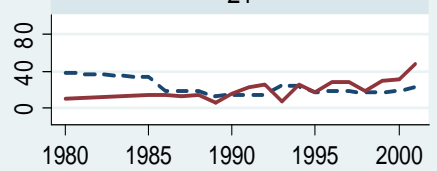

2

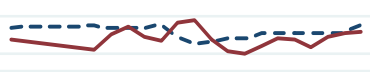

6

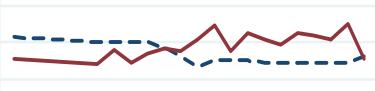

10

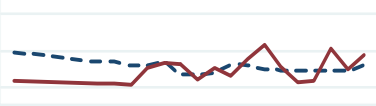

14

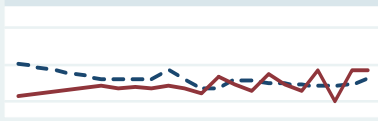

18

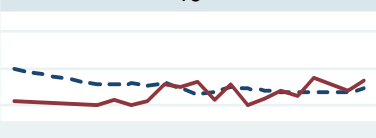

22

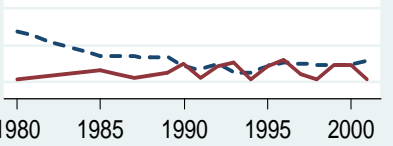

3

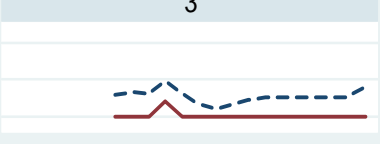

7

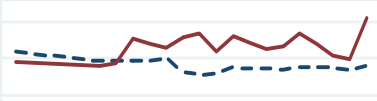

11

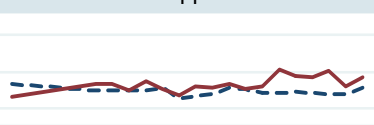

15

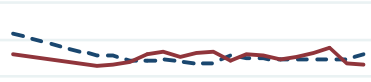

19

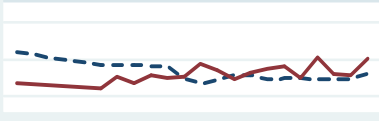

23

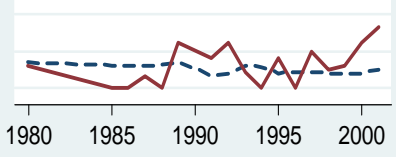

4

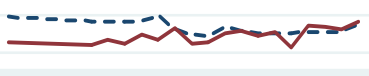

8

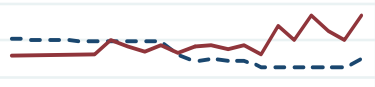

12

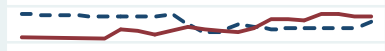

16

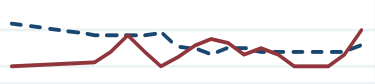

20

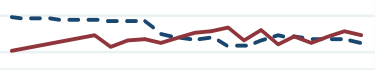

24

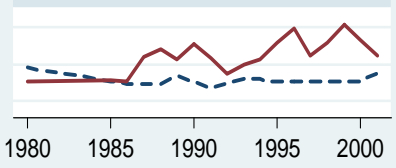

\section{— Tarifas (\%) Ta de informalidad (\%)}

1: Elab. de prod. alimenticios; 2: Elab. de bebidas; 3: Elab. de prod. de tabaco; 4: Fab. de prod. textiles; 5: Fab. de prendas de vestir, excepto calzado; 6: Curtido y adobo de cueros; fab. de maletas, bolsos de mano y artículos de talabartería y guarnicionería; 7: Fab. de calzado; 8: Prod. de madera y fab. de prod. de madera y corcho, excepto muebles; fab. de artículos de paja y de materiales trenzables; 9: Fab. de muebles; 10: Fab. de papel y de prod. de papel; 11: Editoriales e imprentas; 12: Fab. de sustancias y prod. químicos; 13: Fab. de prod. de la refinación del petróleo

y combustible nuclear; 14: Fab. de prod. de caucho; 15: Fab. de prod. de plástico; 16: Fab. de vidrio y prod. de vidrio; 17: Fab. de otros prod. minerales no metálicos; 18: Fab. de metales comunes; 19: Fab. de prod. elaborados de metal, excepto maquinaria y equipo; 20: Fab. de maquinaria, excepto electrica; 21: Fab. de maquinaria y aparatos eléctricos n.c.p.; 22: Fab. de vehículos automotores, remolques y semirremolques; 23: Fab. de instrumentos médicos, ópticos y de precisión; 24: Industrias manufactureras n.c.p. 